Title:

Creating Convivial Affordances: A Study of Virtual World Social Movements

\author{
Running headline: \\ Creating Convivial Affordances
}




\title{
Creating Convivial Affordances: A Study of Virtual World Social Movements
}

\begin{abstract}
The study of technology and societal challenges is a growing area in information systems research. This paper explores how social movements can use virtual worlds to raise awareness or create safe spaces for their members. As social movements move into virtual worlds, the technical environment becomes more important. This paper presents an interpretive field study using netnographic research and empirical data from a study of a lesbian, gay, bisexual, and transgender social movement in World of Warcraft. This paper takes the position that an understanding of affordances is required for users to be able to create convivial outcomes to shape the use of virtual worlds for their own goals and intentions. The paper presents the concept of convivial affordances, which brings together the theories of affordances and conviviality, and suggests that social users can shape IT artefacts through a creative combination of affordances for their specific goals, and with community involvement.
\end{abstract}

Keywords: virtual worlds; social movements; affordances; conviviality; qualitative; netnography 


\section{INTRODUCTION}

There is a growing research interest in technologically supported social movements (e.g. Selander \& Jarvenpaa, 2016; Zheng \& Yu, 2016). Social movements aim to bring about social, cultural, or political change, or awareness through collective action, and consist of groups of people who share a collective identity (Oh, Eom, \& Rao, 2015; Staggenborg, 2011). Examples of a social movement are environmental, peace, student, women's and lesbian, gay, bisexual, and transgender (LGBT) movements (Staggenborg, 2011). Social media is a popular tool for social movements (Kim, Kim, \& Yoo, 2014; Zheng \& Yu, 2016). However, there is limited work on what virtual worlds mean for social movements (Blodgett \& Tapia, 2011; Robinson, 2008).

Virtual worlds become places where social movements can recruit new members, promote themselves, and conduct online activities. Because virtual worlds are more immersive than social media (Wasko, Teigland, Leidner, \& Jarvenpaa, 2011), they allow for a broader range of social movement activities, for example, virtual parades (Blodgett \& Tapia, 2010). Therefore, more socio-technical research with solid theoretical foundations is required (Cao, Basoglu, Sheng, \& Lowry, 2015) to addresses the social nature of technology (Kling, Rosenbaum, \& Sawyer, 2005) for social movements. A better understanding of how technologies are used in particular ways, and how social influences shape the technology within a particular social context (Benbasat \& Zmud, 2003; Orlikowski \& Iacono, 2001), is required.

This paper analyses empirical data collected from an LGBT social movement in World of Warcraft (WoW), a virtual world game made by Blizzard Entertainment. This paper uses two theoretical foundations: conviviality of tools, and affordances. Conviviality of tools are defined as "autonomous and creative intercourse among persons and the intercourse of persons with their environment" (Illich, 1973 p. 10), and the propensity for sharing and strengthening bonds within a community (Germov, Williams, \& Freij, 2010; Guercini \& Ranfagni, 2016). This paper proposes that the creation of convivial outcomes relies on a deeper understanding of how social users can exploit the affordances of technology for their specific goals. To explore this, we consider Majchrzak, Markus, and Wareham (2016)'s argument that studies of technological societal change should include affordances of the IT artefact. Therefore, the second theoretical position is that affordances (Leonardi, 2013) are the fundamental underlying concept for the creation of convivial outcomes. This paper 
expands on previous research of affordances for collective action (Zheng \& Yu, 2016). Affordance research has been primarily used in organisational contexts (e.g. Leonardi, 2013; Strong et al., 2014). However, this paper will explore affordances from a societal context, within virtual world games. The paper addresses the following research question: how do online social movements exploit technological affordances to create a convivial outcome? The unit of analysis for the study is the social movement (a group of social users).

The paper uses netnography to study and engage with an LGBT social movement in WoW. This paper makes two theoretical contributions. The first is the development of convivial affordances, which brings together the theories of affordances and convivial tools, and suggests a process to enable social users to shape IT artefacts. The second theoretical contribution is the development of theories to understand online social movements. This study also provides some practical implications of how virtual worlds can be used by social movements.

This paper is structured as follows. First, the contextual and theoretical background to this study is presented. The paper then presents the methodology and empirical findings. Finally, the paper discusses the theoretical and practical contributions.

\section{CONTEXTUAL BACKGROUND}

\subsection{Virtual Worlds}

Virtual worlds are online environments where users create an avatar which enables them to interact with other users. Two popular virtual worlds are Second Life (SL) and WoW. Virtual worlds are more immersive than social media such as Facebook or Twitter (Wasko et al., 2011) as they allow forms of socialness unlike other technologies (Goel, Johnson, Junglas, \& Ives, 2013). Avatars offer affordances of a 'real' human body (Schultze, 2010), enabling exploration of these immersive technical environments and interactions with other users (Stanney, Hale, \& Zyda, 2015). Virtual worlds contain visual representations (Martončik \& Lokša, 2016) of objects such as trees, rivers, mountains, and may look like the physical world (Castronova, 2007), or a world based on fantasy (Schultze \& Rennecker, 2007).

Nevo, Nevo, and Kim (2012) argue that virtual worlds can be used for hedonic and social purposes and can equally be used in workplace environments. Zhou, Jin, Fang, and Vogel (2015) explored the social aspects of virtual worlds by examining indulgence and individualism. Their findings suggest that developers of virtual worlds should localise their designs to specific markets by considering cultural values. Furthermore, in terms of social 
connections with other users (through avatars), Chesney, Chuah, Hui, Hoffmann, and Larner (2014) examined friendships in virtual worlds. They argue that friendships are impacted by avatar communication, avatar location, and avatar appearance.

\subsection{Online Social Movements}

New Social Movements (NSM) describe a specific type of social movement emerging from advanced capitalist societies. As opposed to social movements centred around the distribution of wealth, NSMs focus on the collective search for identity and seek new social spaces where they can experience and define novel lifestyles (Johnston, Laraña, \& Gusfield, 1994). NSMs define their collective identities through sources such as gender, sexuality, and ethnicity (Buechler, 1995). Collective identity also considers shared values, and experiences that connect individuals (Staggenborg, 2011). These explain how movements emerge; how people become motivated to participate in collective action; and how strategic choices are made (Polletta \& Jasper, 2001). They use a wide variety of protest tactics to encourage social change and influence public opinion (Staggenborg, 2011). Tactics tend to be pre-planned and highly dramatic forms of demonstration, sometimes with costumes or other symbolic representations (Tarrow, 1994).

The Internet has played an essential role in initiating and steering social movements (Postmes \& Brunsting, 2002) as they take advantage of the Internet's capabilities (Leizerov, 2000), and is more suited towards persuasive collective action rather than confrontational action (Brunsting \& Postmes, 2002). The Internet enables social movements to communicate, generate information, distribute information, and receive feedback. The decentralised and user-generated content characteristics of the Internet align well with the nature of NSMs (Salter, 2003). Online movements have the freedom to operate in an entirely new fashion. In an online movement, many different movement members may approach the primary objective of the movement with their preferred methods and styles, and provide several pathways for interested individuals to participate in achieving the goals of the movement (Friedland \& Rogerson, 2009).

Much of the recent online social movement literature has focussed on social media (Miranda, Young, \& Yetgin, 2016). For example, Wilkins, Livingstone, and Levine (2019) explored how collective action in social media can lead to increased future actions. However, much of the research in this area frames social media as a resource or a tool for facilitating cheaper and faster coordination, while black-boxing the technology and treating it like an 
object (Stewart \& Schultze, 2017). Therefore, deeper socio-technical lenses are required to understand the relationship between collective action and technology use. Social movement theories have been applied to understand online social movements in many studies; however, these theories developed in pre-online times. Therefore, we need better theoretical approaches to conceptualise the interactions among technology, social movement members, and their environments (Hara \& Huang, 2011).

Recently, affordances have been used to theorise the role that technology plays in online social movements. By exploring collective engagement through microblogging, Vaast, Safadi, Lapointe, and Negoita (2017) introduced connective affordances, which extends the relational nature of affordances to the interdependence among users, and the effects this has on what the emerging roles of what users can do with the technology. While Zheng and Yu (2016) argue that the functional affordances of Weibo (a Chinese social media platform) are socialised through collective action, they define social affordances as being enacted within the social practices performed within the collective action processes of the online social movement. Furthermore, affordances of technology give online social movement members new insights and strategies, but more research is required from IS researchers to understand the use of affordances for social good (Young, Summers, \& Coursaris, 2019).

\subsection{LGBT Social Movements and Online Spaces}

Contemporary LGBT movements can trace their origins to Amsterdam, Copenhagen, Paris, and Los Angeles where movement members renewed their efforts after World War II to create gay-friendly spaces (Adam, Duyvendak, \& Krouwel, 1999). The Stonewall Riots in 1969 were a turning point for the acceptance and liberation of LGBT communities (Vorobjovas - Pinta \& Hardy, 2016). As LGBT people suffer from discrimination in many societies, the topics that local movements have dealt with are similar. For example, fighting discrimination and establishing public spaces of their own (Adam et al., 1999). Many countries around the world celebrate gay pride, often with dance parties, public shows, and pride parades. The rainbow flag has become the symbol for the global gay rights movement and is often hung outside establishments to indicate they are either gay-owned or gay-friendly (Sibalis, 1999).

LGBT issues continue today, for example, Mowlabocus (2010) argues that the mainstream culture often identifies gay men as "other". Therefore, it is not uncommon for LGBT individuals to use online spaces to overcome feelings of isolation (Campbell, 2004). 
The Internet is often used as a space for stigmatised members of society to come together to share grievances (Durkin, 2004). When LGBT individuals come together as a community, they can support each other (Savage, Harley, \& Nowak, 2005), and can become more aware of members' similarities within the group and can overcome threats from outside the group (Baumeister \& Vohs, 2007; Maki, 2017). Some examples of online spaces include, for example, video-sharing technologies on sexual social networking sites (Kreps, 2013), or online sex groups (Ashford, 2009). Virtual worlds enable LGBT individuals to come together to express their identity (Cabiria, 2008). In game-based virtual worlds, these players are known as 'gaymers' (Shaw, 2012). Gaymers have a history of being discriminated against by game developers, game administrators, or other players. For example, in 2006, a WoW player advertised her character as LGBT, and faced an immediate ban by Blizzard, illustrating that homophobia is a real concern in virtual worlds (Shaw, 2012) resulting in protests by players. Blizzard ultimately changed their policies to allow for LGBT representation in the game. Despite recent social and political advancements in many western countries, there are still local and global tensions for LGBT rights (MacCartney, 2018).

Cabiria (2008) explored how virtual worlds can act as safe havens for gays and lesbians and other marginalised people where they can develop positive coping skills, and explore their identities. Blodgett et al. (2007) examined gay and lesbian issues in virtual worlds and proposed that further research is required to understand the diversity of users in virtual worlds.

\section{THEORETICAL BACKGROUND}

\subsection{Conviviality}

Online social movement research demonstrates that the Internet can foster collective identity and solidarity among movement members, and can also provide a space for social movements to exist and undertake their activities (Hara \& Huang, 2011). Online collective identity can also emerge as participants are part of a broader online community (Garrett, 2006). Technologies also can allow for social movements to shape their collective action, to promote participation (Benford \& Snow, 2000), and for community development (Hara \& Huang, 2011), through various methods (Friedland \& Rogerson, 2009). Therefore, conviviality becomes a useful theoretical lens through which to analyse online social movements. 
Conviviality considers the nature of human togetherness (Nowicka \& Vertovec, 2014). Illich (1973) describes 'tools for conviviality' which “can be easily used, by anybody, as often or as seldom as desired, for the accomplishment of a purpose chosen by the user" ( $\mathrm{p}$. 22). Bradley (2016) explains this means that people should not be reliant on specialists controlling tools or technologies which are necessary for a good life. Guercini and Ranfagni (2016) further argue that conviviality represents a tool that can be modified to one's intentions. Conviviality is distinct from the concept of community, as it represents a sense of belonging and the reaping of benefits of belonging to a community (Guercini \& Ranfagni, 2016; Lloyd, 2002).

Despite the broad range of disciplines using conviviality, there is little empirical work on conviviality in IS. Ameripour, Nicholson, and Newman (2010) explored how the Internet can contribute to conviviality in Iran using two case studies of blog campaigns. To do this, they used four characteristics which define convivial tools (Illich, 1973). The four criteria for convivial tools are (Ameripour et al., 2010 p. 246):

1. Users, rather than the designers of the technology, must have the power to shape it according to their tastes, desires and needs.

2. Convivial tools must promote communities and encourage and maximise communication among the members of society.

3. Convivial tools must make the most of the energy of individuals, and maximise and encourage creativity and imagination of users.

4. Users of convivial tools must not be mere consumers, but also producers and contributors to the technology.

Conviviality can be considered the desired state for actors to shape the technology for their goals. However, how users reach that desired state is still uncertain. There remain questions regarding the mechanisms within IT systems which allow users to shape the tool for their desired needs. The theory of conviviality is limited in that it lacks an understanding of the functional elements within technology which support the creation of convivial outcomes. An analysis of socio-technical systems requires a deeper set of tools to understand how social structures are shaped and enabled through the functional elements designed into IT systems. This paper addresses the question of how social users can achieve their desired goals, by proposing that studies of socio-technical systems to create convivial outcomes should also include an analysis of affordances (Majchrzak et al., 2016). 


\subsection{Affordances}

Affordances are the possibilities of action that animals have within an environment (Gibson, 1977). Initially, affordances were viewed as a property of the environment (Turvey, 1992). More recently, affordances are considered as relational (Hutchby, 2001), between the abilities of an animal (including humans), and the features of an environment (Chemero, 2003; Stoffregen, 2003). Therefore, affordances become the property of the relationship (Hutchby, 2001; Stoffregen, 2003). Affordances are either enabling or constraining, which allow for an animal to engage in an activity: such as swimming, climbing, writing, or printing a document. Affordances cannot be freely variable (Hutchby, 2001), and multiple affordances can arise from a single animal-environment relationship (Volkoff \& Strong, 2013).

Hutchby (2001) developed the idea that affordances of technologies may have different interpretations by different users. Rappert (2003) later suggested that Hutchby's claims were misguided:, "the notion of affordance is not much help in elaborating the implications of technology or the inter-relatedness of the technology and the social" (p.574). Responding to this criticism, Hutchby (2003) argued that Rappert was more interested in sociological claims about technology, rather than ordinary societal members use of technology. Ordinary users are more concerned with what the technology can and cannot do. The key differences in opinion are that Rappert (2003) prioritises technologies as an object of attention, while Hutchby prioritises actions - the interactions which involve some degree of technology mediation (Hutchby, 2001, 2003).

For affordances in technical contexts, the original animal-environment relationship becomes a human-artefact relationship (Zheng \& Yu, 2016), and is useful for examining previously unrecognised roles of technology (Majchrzak \& Markus, 2012; Tim, Pan, Bahri, $\&$ Fauzi, 2018). An affordance is the relation between users and technology within specific usage situations, and are the possibilities of individual behaviour offered by a technical object (Grgecic, Holten, \& Rosenkranz, 2015; Markus \& Silver, 2008). Affordances only exist with the presence of users' intentions (Chemero, 2003; Grgecic et al., 2015), which may differ from other users' (Volkoff \& Strong, 2013). Therefore, depending on the usage situation, different individualised affordances may arise from the same technology (Leonardi, 2013). Other research has presented functional affordances which are specific to Wikis (Mansour, Askenäs, \& Ghazawneh, 2013), online knowledge sharing in social media (Majchrzak, Faraj, Kane, \& Azad, 2013), and new forms of organising (Zammuto, Griffith, Majchrzak, Dougherty, \& Faraj, 2007). 


\subsection{A Framework of Affordances for Convivial Outcomes}

Norman (1999) argued that when designing IT artefacts, the affordances of the artefact should be clear to the user. For example, a button is designed to show that it should be clicked. According to Grint and Woolgar (1997), technologies are written by developers, who impose meaning into the design, and are read by the user, which may involve multiple interpretations and impact on the social realities of technology. However, not all IT artefacts are treated the same by different users, depending on their spatial, temporal, and social contexts (Orlikowski \& Iacono, 2001).

Much of the research on conviviality within IS focusses on the design of technology (e.g. Johri \& Pal, 2012; Wastell, Kawalek, Langmead-Jones, \& Ormerod, 2004), or explores the conviviality of technology without considering the functional elements of how convivial outcomes were created (e.g. Ameripour et al., 2010; Takavarasha \& Masunungure, 2016). Johri and Pal (2012) discussed conviviality for the empowerment of users to exercise agency over the design of technologies for their use, providing an avenue for the enrichment of users' lives and self-expression through design. The work of Johri and Pal (2012) focused on initial technology designs before implementation. Thus users have direct input at an early stage of technology development.

Conviviality research focussing on technology use after implementation (e.g. using technology rather than designing it) has taken for granted the functional elements of the technology in the creation of convivial outcomes. For example, Takavarasha and Masunungure (2016) and Ameripour et al. (2010) both examine Internet-based campaigns for political communication using a convivial lens, but the technical means in which these convivial outcomes were created is overlooked. Therefore, this paper argues that the creation of convivial outcomes by social users after technology development means that users must focus on the interpretation and use of affordances. For example, as social movement users have no input in the design of virtual worlds, the only way to create convivial outcomes is through their collective interpretation and use of affordances.

This paper argues that affordances are the necessary precursor for the creation of convivial outcomes. As social movements interpret technologies in different ways, they may use affordances in new and different ways, which opens up new convivial opportunities. This paper expands on Hutchby (2003)'s argument that the affordances enabled by a technology play a role in the actions of the users. Two elements are critical to this argument, based on the commonalities between the affordance lens and the conviviality lens: first, the goals of the 
actors, and second, their use or actions (Ameripour et al., 2010; Hutchby, 2003; Rappert, 2003; Strong et al., 2014). Based on the discussion above, a conceptual framework was developed. For a particular IT artefact: 1) an affordance is interpreted by a group of social users; and 2) depending on their goals, the social users can use the affordances to create a convivial outcome. A simple illustration of this argument uses Hutchby (2001)'s example of a bridge affording the possibility of 'crossing'. Social movement members with the goal of creating awareness for a social and political cause may cross a bridge while simultaneously hanging banners from the side of the bridge, chanting, or some other creative use of the crossing affordance enabled by the bridge, thus using the crossing affordance enabled by the bridge to create a convivial outcome. These ideas were used to develop the data collection and analysis for this study.

\section{METHODOLOGY}

\subsection{The Social Movement: Alpha}

The social movement explored in this study is known as Alpha. Any long-term group in WoW must form a guild. The Alpha guild was established in October 2006 with the goals to: "better service the LGBT community and offer a safe, inclusive place to game for members of any sexual orientation or gender identity". Alpha is the largest special interest guild and also holds many regular activities inside WoW, such as an annual pride parade with floats, model competitions, dance parties, and guild photographs. Alpha also has a website with discussion forums. When the study began in early 2010, Alpha had approximately 5,000 members (players). By early 2013 the membership had grown to 7,800.

\subsection{Data Collection}

The author conducted an interpretive field study using netnographic research - a form of online ethnography using the Internet (Kozinets, 2010; Myers, 2013) - to study and engage with Alpha in WoW. The role of the researcher was that of an involved researcher (Walsham, 2006). The principles of interpretive field work (Klein \& Myers, 1999) were applied throughout the study, and are detailed in the appendix. After obtaining permission from Alpha leaders, the researcher joined the movement. In virtual worlds, the player must create an avatar which becomes the researcher's identity when immersed in the research environment (McKenna, Myers, \& Newman, 2017).

The primary sources of data from this study come from participant observations from one and a half years of fieldwork, discussion forum data (128,773 posts downloaded), and 
chat logs. Additional data sources included documents from Alpha's website, other WoW websites, patch notes (changes to the game's implementation), and informal conversations with other WoW players. Multiple data sources enabled triangulation for the analysis. In total, the lead researcher spent over 1,600 hours engaging with Alpha.

The discussion forum data was also an extremely valuable data source. In some ways, it can be argued that this data is more "authentic" than interview data. As Myers and Newman (2007) point out, the interview is an artificial situation. The interviewee is prompted by a stranger (the interviewer) to answer some questions at a specific point in time, whereas discussion forum data records what people thought and posted at the time, and is continually updated.

Field notes from the participant observation were recorded differently to traditional ethnographic studies. On occasions, Alpha members would meet virtually with their characters and participate in activities such as the pride parade. The researcher would also participate, for example, marching in the parade. Marching required the use of both hands to control the character's movements with the keyboard and mouse, which meant he did not have a free hand for note taking. Therefore, he took a series of screenshots during these events to record what was happening. Later, the screenshots were examined, and field notes recorded.

\subsection{Data Analysis}

Following the recommendations of McKenna et al. (2017), the dataset was reduced through three methods. First, keyword searches were used (e.g. parade, chat, LGBT, membership, guild, add-on). Second, the researcher aligned the discussion forum data with the patch note dates. For example, if a patch was released on a specific date, forum posts made close to (before or after) the same date were extracted where Alpha members specifically discussed the implications the patch would have on Alpha. Third, the researcher filtered the posts using keywords from the theoretical perspectives (e.g. community, goals, society), and with keywords from his knowledge of the game (e.g. zones, mods, names of specific affordances).

Data were analysed using the conceptual framework presented earlier using Leximancer and NVivo. Leximancer uses content analysis to analyse large qualitative datasets and displays the results in a visual format called themes. Leximancer then allows for the extraction of the text that created the themes and displays how the themes are related. The text was also manually coded in NVivo using thematic coding (Saldaña, 2016). Using the automatic Leximancer approach, combined with the manual NVivo coding, provided 
multiple rounds of coding. Additional details of the Leximancer analysis and other methodological implications and issues faced during this research have been published in McKenna et al. (2017).

The other primary data source was screenshots (images). Diaz Andrade, Urquhart, and Arthanari (2015) advocate the use of images as part of the research process. The researcher took the screenshots himself using a built-in screenshot tool within WoW, which was then loaded into NVivo for thematic coding.

\section{NETNOGRAPHIC CASE ANALYSIS}

This section will present the netnographic analysis as an account of the researcher's experience in playing the game, through a mixture of storytelling, personal experience, and empirical evidence. First, the researcher's experience of ordinary gameplay will be illustrated and will detail the researcher's experience of gameplay before joining Alpha, providing a base in which to contrast the next section on Alpha's convivial use of WoW. All names are disguised.

\subsection{Affordances of World of Warcraft for Ordinary Game Play}

WoW is a game where the two factions (Alliance or Horde) are at war with each other. Ingame, the characters of opposing factions cannot communicate with each other. The first step is to create a character and decide which faction to play. Characters replicate a physical body in a virtual space and afford the player to move about and interact with other players through various abilities (Schultze, 2014). The researcher created an Orc Warlock named Thirl, on the Sirader server. Once Thirl was created, he was then "born" into the virtual world. The first thing the researcher noticed was the virtual space in which Thirl was situated.

The game design and associated technical infrastructure developed by Blizzard creates the affordance of a virtual space (Goel, Johnson, Junglas, \& Ives, 2011). The world within this virtual space is known as Azeroth, which is divided up into zones. When a player starts a new character, they are born into a specific zone (depending on the characteristics chosen during character creation). Thirl was born as a level 1 character into the zone known as Durotar, which is suitable for new characters below level 20. Each zone is suited to characters of a certain level range, for example, levels 20 to 30. Once a character has earned enough experience points, they will gain a higher level. Therefore, the main goal for players is to 'level up'. Levelling up increases the strength and power of the character, and allows them to learn new spells and abilities which may only be available once a character has 
achieved a higher level. Levelling is also important because it affords a character to explore higher level zones within Azeroth.

The researcher began to increase Thirl's level by earning experience points. Experience points can be earned through the questing affordance. Thirl approached a non-player character (a quest giver), who detailed the first quest to be completed. The quest giver details the tasks which must be completed, for example, kill in-game monsters or perform other activities which reward experience points (McKenna, Gardner, \& Myers, 2010). Questing is mostly achieved through solo gameplay (with some exceptions). As Thirl was completing quests, and exploring the virtual space around him, the researcher became aware that he was not alone. The virtual space affords Thirl to interact with other players through chat, or physical interactions such as waving to each other or completing quests together.

Later, the researcher realised that WoW provides an affordance where players group together into long term groups called guilds, which contains a guild chat for private chat between guild members (Crenshaw \& Nardi, 2016). Guilds consist of several players within one of the two factions, which provide opportunities for assistance with quests, social interactions, and protection from rival factions (Brignall \& VanValey, 2007). While many social activities take place within guilds, this only accounts for $56 \%$ of social activities in WoW (Williams et al., 2006). More recently, WoW has become less of a sociable space, with fewer opportunities to work on virtual game goals with other players, making the activities of the LGBT movement more interesting, as the social architecture of the game provides or limits opportunities for social engagement (Braithwaite, 2018).

WoW also affords players to create and use third-party add-ons to the game, which enhances gameplay in various ways (Taylor, 2009). Any player at their discretion may also install add-ons to assist with aspects of game-play. Many of these add-ons are freely available to download online and can easily be installed into WoW. Add-ons are used for a wide range of reasons, for example affording a player to navigate quests and raids, display extra map features, help players to auction virtual items, or to help players fight monsters.

Only those affordances relevant to the context of this study, or to provide a general overview of WoW have been presented, for other examples see Crenshaw and Nardi (2016).

\subsection{World of Warcraft for the LGBT Movement}

After playing the game for several weeks, and Thirl venturing into higher level zones, the researcher became aware of a high number of other players with the Alpha name label floating above their characters' heads. After chatting with some of these players, he 
discovered that they were a member of an LGBT guild. Upon further discussions with them, he discovered that they were planning a virtual pride parade. The researcher joined Alpha and attended the pride parade.

Through interactions with Alpha members, the researcher realised that Alpha had very different goals within the game than those of ordinary gameplay. As Alpha members also partake in ordinary gameplay, the above descriptions of ordinary gameplay also apply to them. However, as a collective community, there are some additional specific goals related to their LGBT movement. These create vastly different uses of the game. Therefore, Alpha members have parallel goals: ordinary gameplay (discussed above), and social support (discussed next).

Additionally, there are two sub-goals for Alpha, which aid in creating the LGBT social support: community building, and periods of activity. These goals, and the affordances used to achieve them, are illustrated in figure 1. These goals and affordances discussed will be used to structure the remainder of the analysis of Alpha's creation of convivial outcomes.

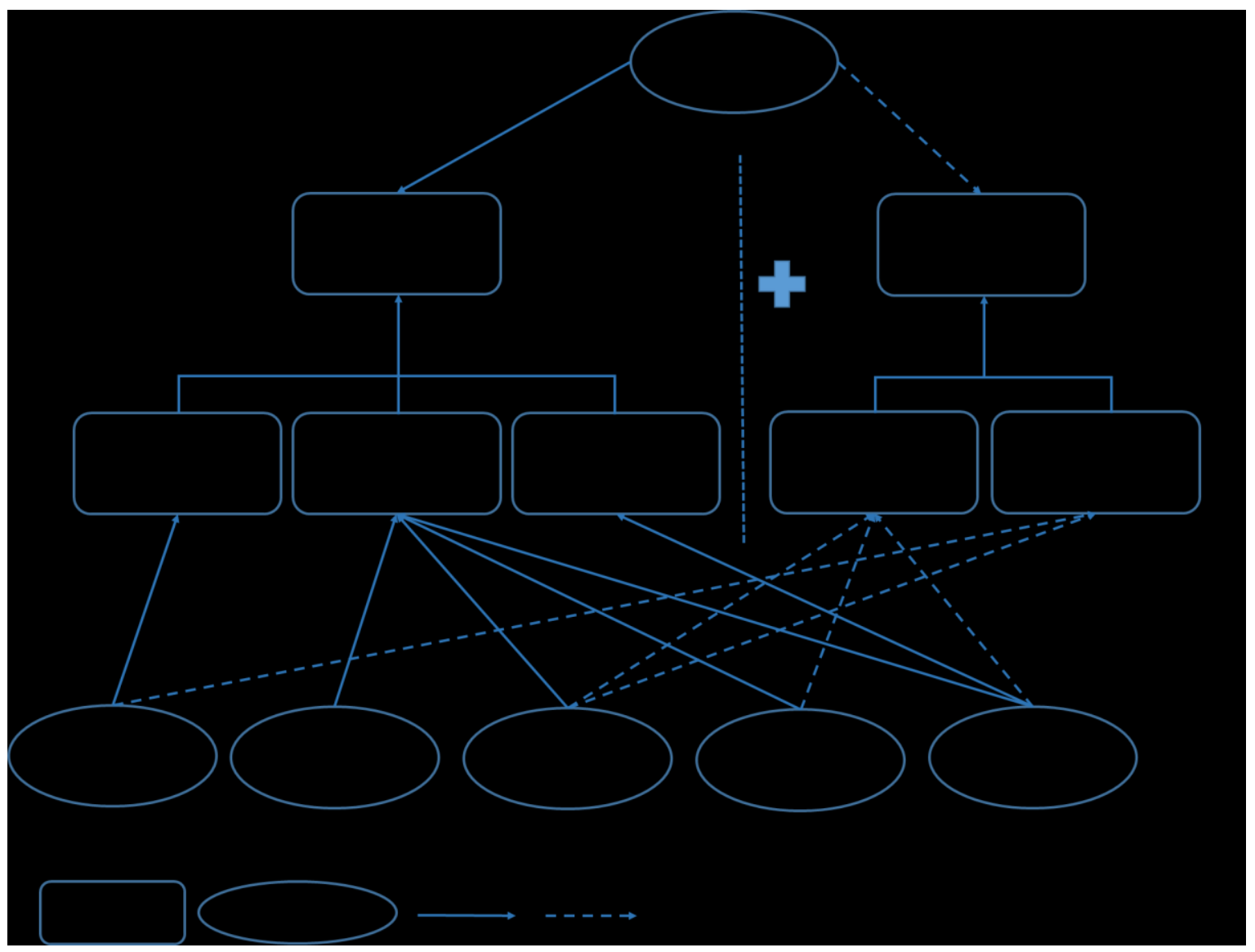

Figure 1: Goals and their affordances 


\subsection{Goal: Community Building}

The community building goal is achieved through the creative combinations of membership, add-ons, guilds, and communication affordances.

\subsubsection{Membership and Add-ons Affordances}

The reasons members joined Alpha were not primarily for gameplay. Many members join for a desire to come together as an LGBT community, to share experiences, and support each other, while also playing the game together. To afford membership, a player must enroll their character(s) into Alpha. Structurally, Alpha is a family of sub-guilds (although collectively referred to as 'a guild'). In January 2010 Alpha consisted of six sub-guilds and had a total of 5,737 unique members. Alpha has several affordances available for recruiting new members. One way is by facilitating chat to make recruitment posts, for example:

"Alpha is an LGBT-Friendly progression guild on Sirader. What is LGBT? Lesbian, Gay, bisexual/pansexual, and transgender [...]. We ask that you be a Hardcore raider and be comfortable in + supportive of an LGBT atmosphere." [Shape Technologies; Promote communities].

This allowed Alpha to increase their visibility within WoW, grow their community, and to actively seek out new members by using the membership affordances available to them. These affordances were exploited using features such as the server-wide chat channel, where any player can see these announcements.

The researcher became aware of Alpha through the visibility of guild labels. WoW affords players to view the guild name that other players belong to as a text label above their avatar's head. Because of this affordance, Alpha has been able to use WoW to promote its movement community, just by Alpha members travelling around the virtual spaces (playing the game). The visibility of Alpha was increased to the general population of the server, leading to increased membership and community growth, and awareness of Alpha's existence. Over time, this increased awareness meant that the server became known as the gay-friendly server on WoW, as Alpha began to shape the technology for their desires.

Member: I was visiting a friend on Sirader and saw in trade chat that this was where all the gay people were, Applied, transferred my main toons and dragged my boyfriend along too. [Promote Communities] 
Member: I've seen a lot of Alpha members on Sirader and asked one of the members how to join. [Promote Communities; Shape Technology]

There are also members who specifically seek out LGBT groups in WoW. Over time, knowledge of Alpha increased, and many new members discovered LGBT through word of mouth or search engines. Alpha was very active in increasing their visibility, as knowledge of them spread outside of WoW. Thus Alpha were no longer just consumers of technology but were able to use it to raise awareness for LGBT issues to a broader audience.

Member: I heard about you all from gaygamer.net, and also a friend on another server. I thought I would make an alt here to see how full of awesome you all are, and I am very happy I did. [Producers of Technology]

Member: I spent a lot of time googling for gay guilds... and first spent a number of months in another server $w / f e w$ homosexuals. I played Alliance before trying Alpha casually and getting hooked on how much bigger the guild is (and n2f of course).

[Promote Communities]

This member refers to $\mathrm{n} 2 \mathrm{f}$ (meaning name to face), an add-on developed by Alpha for their exclusive use to allow members to upload a photo of themselves. The community building goal also relies on the add-ons affordance. This add-on then allows other Alpha members to "right click" the mouse button on another player's character to display a photo of that player in-game. For privacy reasons, an example of this will not be illustrated. This add-on enables LGBT to use WoW in a convivial manner to shape the technology for their desired use, enabling them to promote a more communal and real aspect of Alpha membership, creating a duality between their gameplay goals and the 'real' nature of their community goals.

N2F Developer: I've written a mod that will display a player's image in-game when you click on their character's name in the chat window. [Producers of Technology; Creativity and Imagination]

Member: 1) it's a great escape from life. 2) A way to socialise with gay people regularly outside of bars. 3) N2F lets me crush on people and forget how I'm not getting laid in real life. 4) I think a huge attraction to the game is very basic to the needs of humanity.... [Promote Communities] 
Member: the person who wrote the add-on and maintains the site is not an officer, just a member who put this all together in his spare time." [Creativity and Imagination]

Because WoW affords the creation of third-party add-ons, this increases the opportunities available to Alpha to develop a convivial environment through the creativity and imagination of their members. There was a period when $\mathrm{n} 2 \mathrm{f}$ was not working correctly and had to be taken offline. It took a while for the developer (an Alpha member) to fix the bugs and to come back online. Many members voiced their thoughts on the matter during the downtime, and after it was re-implemented.

Member: I'm having N2F withdrawal!! It's weird not seeing whom I'm talking to!! Lol Btw, thanks for all your hard work with N2F. [Promote Communities]

Member: If $N 2 F$ went down, I'd have to cancel my subscription. Geeky hot men. Rawr. [Promote Communities]

Member: Thank you hun for fixing name 2 face, now I can see new members. [Producers of Technology]

N2F Developer: Because I Love Alpha I'm adding a few new features to $n 2 f$ in the form of slash commands. I have a few other ideas brewing as well. [Producers of Technology]

Before Alpha was well known, there were times when other players were reporting Alpha to Blizzard's game masters (GM). Other players reported Alpha because someone found their name offensive. In this example, the threats from other players caused Alpha leaders to discuss their continued existence with Blizzard. They argued that as the game affords membership to general guilds, why should it not also afford membership to LGBT focussed guilds?

Member: "Many of you will remember this incident when Alpha's name got temporarily changed to "Zeta" because someone reported our guild name. To clarify, this has happened many times before and, on Blizzard's side, they have a "DO NOT CHANGE THIS GUILD NAME" tag for our guild, just that once in a while one of their GMs do not check before acting on a report. Much thanks to our beloved guild 
leader, who waited for hours on the phone and then threatened Blizzard with the wrath of 5000 homosexuals. " [Promote Communities]

Nowadays, Blizzard's policies are more inclusive and allow for Alpha to exist and use the affordances relating to membership and guild management as they see fit. One GM, responding to further complaints, posted an announcement on the official WoW discussion forums. Through the affordances of membership, Alpha has been able to shape the opinion of Blizzard and other players and use the technology to promote their communities. Blizzard now actively supports Alpha in an official capacity.

Blizzard GM: "Guilds are allowed to organise themselves however they see fit, provided their name is in accordance with our naming guidelines and they do not use their guild make-up to harass other players in the game. [Promote Communities]

Alpha has been able to use the affordances of membership to create a convivial outcome for their goals of community building (Figure 2).

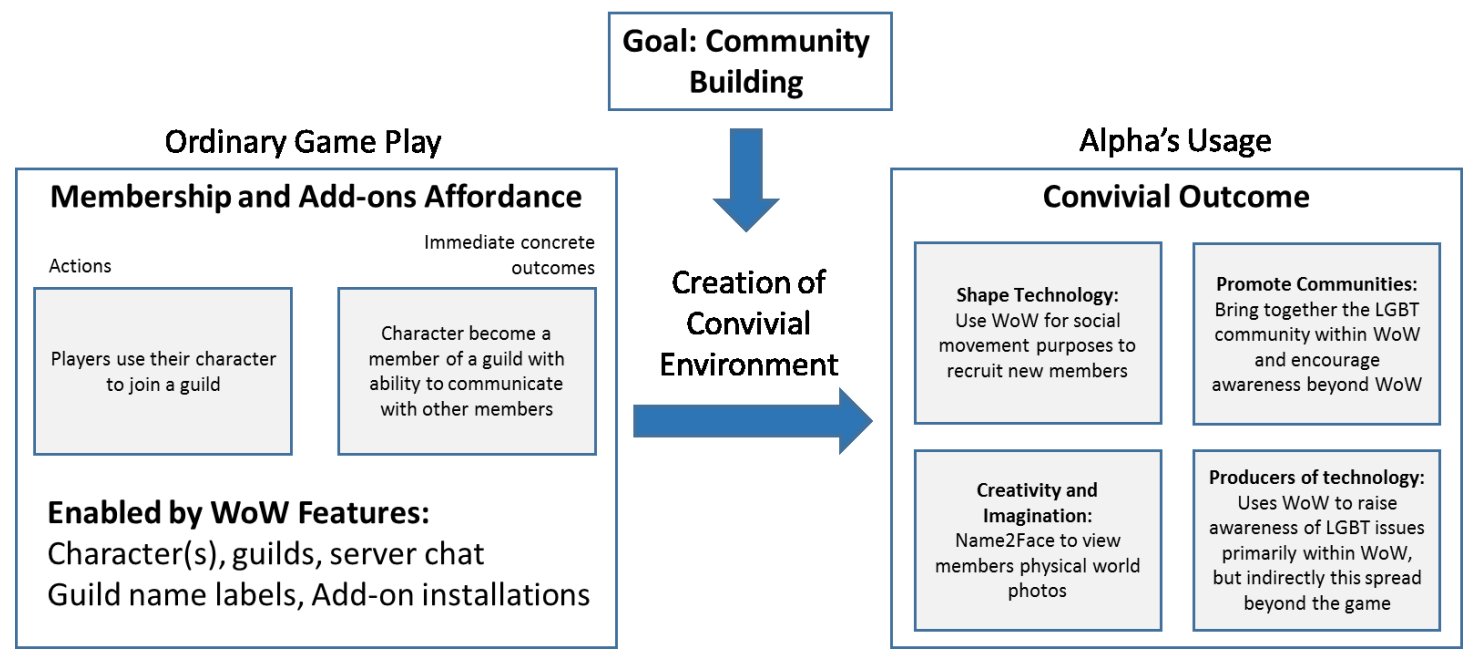

Figure 2: Convivial outcomes of membership for community building

\subsubsection{Guilds and Membership Affordance}

Without a guild, membership would not be possible. In 2010, the membership affordance came under threat due to Blizzard's new implementation of the guild affordance. On 12 October 2010, Blizzard released Patch 4.0.1, changing WoW in such a way to have a significant impact on Alpha's sub-guild structure. During beta testing of the upcoming expansion pack, Cataclysm, Blizzard became aware that large guilds would not function well, 
and they decided to place a hard cap on the number of members a guild can have. The researcher was involved in the beta testing as he received an invitation from Blizzard to take part and to report any bugs or issues back to Blizzard. Therefore, he was one of the first to experience the changes with the guild affordance. Blizzard was planning to implement new guild management systems and realised that larger guilds would have a negative impact on these systems. Therefore, to ensure the smooth running of the guild system, they found that placing a hard membership cap on guilds was necessary. Blizzard made the following announcement about the guild size caps.

"This new guild cap is being enforced for several reasons, but they all factor into a need to control guild sizes in light of new guild systems [...] The larger the guild, the bigger the impact on these systems. We found it necessary to determine a maximum guild size to ensure continued performance now and into the future. The new cap of 600 members is fully supported in the new guild system.

These changes would not impact most guilds in WoW; however, it would have a destructive impact on Alpha due to their current membership size. Many members began to actively voice their opinions about what the potential impact on Alpha would be. Most members agreed that staying together as an LGBT movement was very important and began to suggest solutions to the problem. Some suggested that it may be necessary to split Alpha, and wondered if it could continue to exist if this happened. The leaders argued to Blizzard that this change was unfair. Blizzard refused to backtrack and said:

"While some players have used options including mods and custom chat channels to support large player and guild alliances that number multiples of thousands, groups of that size aren't ideally suited to our design philosophy."

After much discussion with the guild community, Alpha leaders finally decided how to tackle the challenge. They decided that the best action was to begin restructuring sub-guilds. First, they began to remove characters from the main guild who had been inactive for more than 90 days. By January 2012, this process reduced the main guild from 6,200 characters to 3,500. As well as joining guilds, WoW also has the affordance of allowing members to leave a guild. Therefore, many individual players, realising the importance of the restructure, volunteered 
to move some of their characters to one or more of the lesser populated sub-guilds. This allowed Alpha to create a convivial environment by using its features in a way to support their guild restructuring.

Alpha Leader: When patch 4.0.1 goes live (most likely next week), we will reactivate the Alpha guild for all future invites since we won't be able to add any toons to Alpha. We will not be making any other changes or adding any other sub-guilds until we see exactly how the new system works and the results of our advocacy efforts with Blizzard. [Shape technology; Creativity and Imagination]

Blizzard received complaints from many Alpha members, and eventually, they announced that the cap would increase to 1,020 members. By late October 2012, the main guild had 932 characters. By late May 2013, it had 881 characters. Later, to accommodate the movement of characters around the sub-guilds, the number of sub-guilds increased from six to eleven. Recruitment of new members, which is a key issue in social movements, was closed for the main guild and any other sub-guild with a membership population close to the new membership cap. Together, these structural and procedural changes allowed Alpha to continue to exist as an LGBT family while complying with Blizzard's new rules (figure 3).

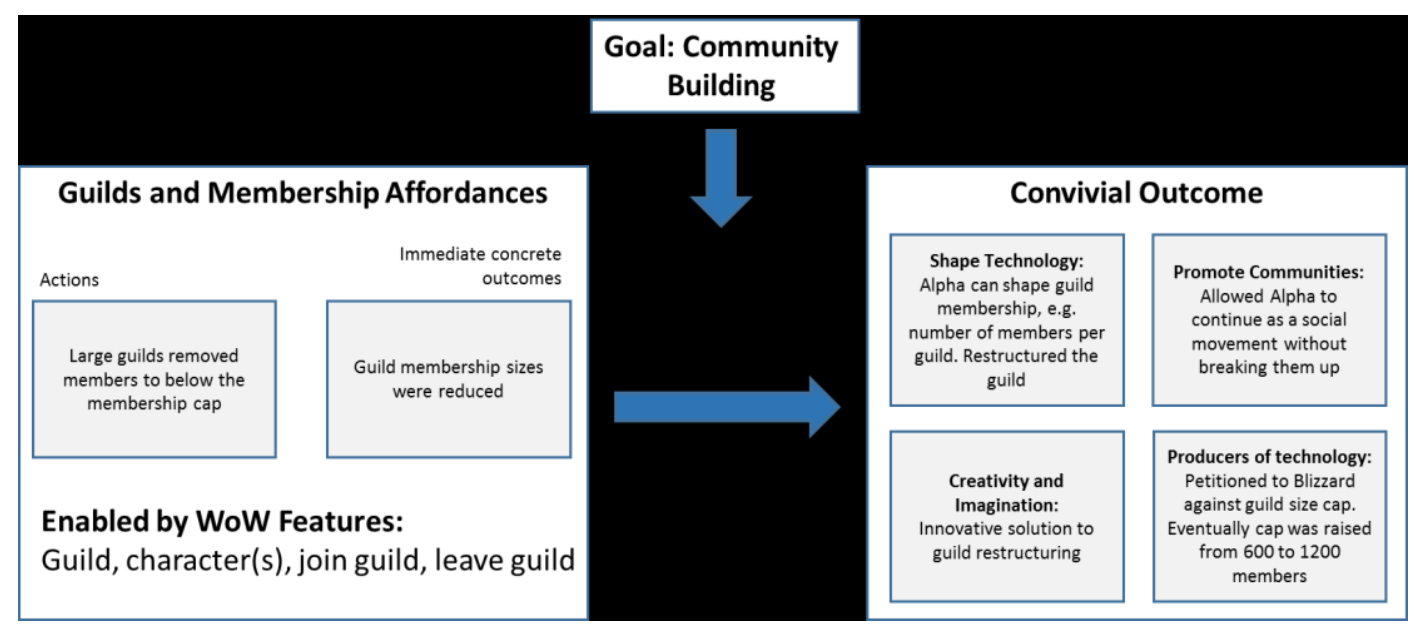

Figure 3: Convivial outcomes of guild re-structuring for community building

\subsubsection{Communications and Add-ons Affordances}

To build communities, Alpha must also use the communications affordance. One of the technical limitations of the chat feature afforded by WoW guilds is that members of one guild (even an affiliated sub-guild) cannot communicate with the members of a different guild. 
Each sub-guild has a private chat channel only for members of that sub-guild. This means that even affiliated sub-guilds such as Alpha, cannot share a chat channel among members. For example, Thirl would be unable to use guild chat to chat with another Alpha member from a different Alpha sub-guild. However, Alpha found a way to create a shared chat channel across sub-guilds by creating an add-on that joins together each of the eight private sub-guild chats into one shared chat. Because it is an add-on (called Guild2Guild), individual players must install it on their game client; otherwise, it will not be possible to see the other sub-guild chats. However, after Patch 4.0.1 (December 2010), the Guild2Guild add-on was no longer compatible with the game which meant that members of one Alpha sub-guild could no longer be able to communicate with other Alpha members in another sub-guild, which of course threatened the viability of Alpha as a coherent social movement. The Alpha leadership discussed how to get around this issue, and made a call to the Alpha membership asking for assistance.

Alpha Leader: During our officer meeting today, we talked a bit about the ongoing Guild2Guild issues, and concluded that it is highly probable that we have the programming talent within our guild to design a better solution. Guild2guild was likely never designed to function with 10 guilds, so our situation is unique and will require that the programmers keep that thought in mind when making it as flexible and stable as possible. To start things out, I would like to find out who we have in the guild with the programming knowledge \& experience who may be willing to work on a team to build a new solution for us. [Shape Technology; Promote Communities; Creativity and Imagination; Producers of Technology]

To overcome this Guild2Guild problem, Alpha used the add-ons affordance to develop a new chat add-on, called Chat2Chat, which re-joined the chats of each Alpha sub-guild. Several members of Alpha answered the call above and used their skills to develop and test Chat2Chat. Many WoW add-ons are published online and are available for other players to download. However, Chat2Chat was developed exclusively for Alpha.

Alpha Leader: The Alpha leadership is very proud to announce the release of Chat2Chat, a new version of Guild2Guild developed in-house by a group of Alpha members with the aim of reducing some of the problems we've been experiencing with Guild2Guild. Over the next couple of weeks, we will be asking all Alpha members to 
stop using Guild2Guild and switch over to Chat2Chat. We would also like to extend a huge, hard, throbbing thank you to Telian and Driliwyr, who were the main architects of this project and put a tremendous amount of time and effort into building this mod to improve the experience of everyone in Alpha. /kiss them next time you see them in-game!

\section{[Shape Technology; Promote communities; Producers of Technology]}

However, the Chat2Chat solution was short lived. In April 2011, Patch 4.1.0 was implemented which again meant that Chat2Chat was not compatible with the game. Alpha was again forced to find a solution to link all sub-guild chats together and was announced as follows.

Alpha Leader: "We have been doing some limited testing on a mod called GreenWall.

Our initial testing has shown great promise, and we would like to move toward the next step of getting our guild members to download this mod in anticipation of a guild-wide test. [Shape Technology; Promote Communities]

GreenWall was an add-on developed by a third-party developer not affiliated with Alpha and was publicly available to download for all WoW players. The testing of GreenWall proved successful and thus was implemented by Alpha. Adds-ons afford Alpha the ability to strengthen their community by enabling communications between members within the Alpha family of sub-guilds (figure 4).

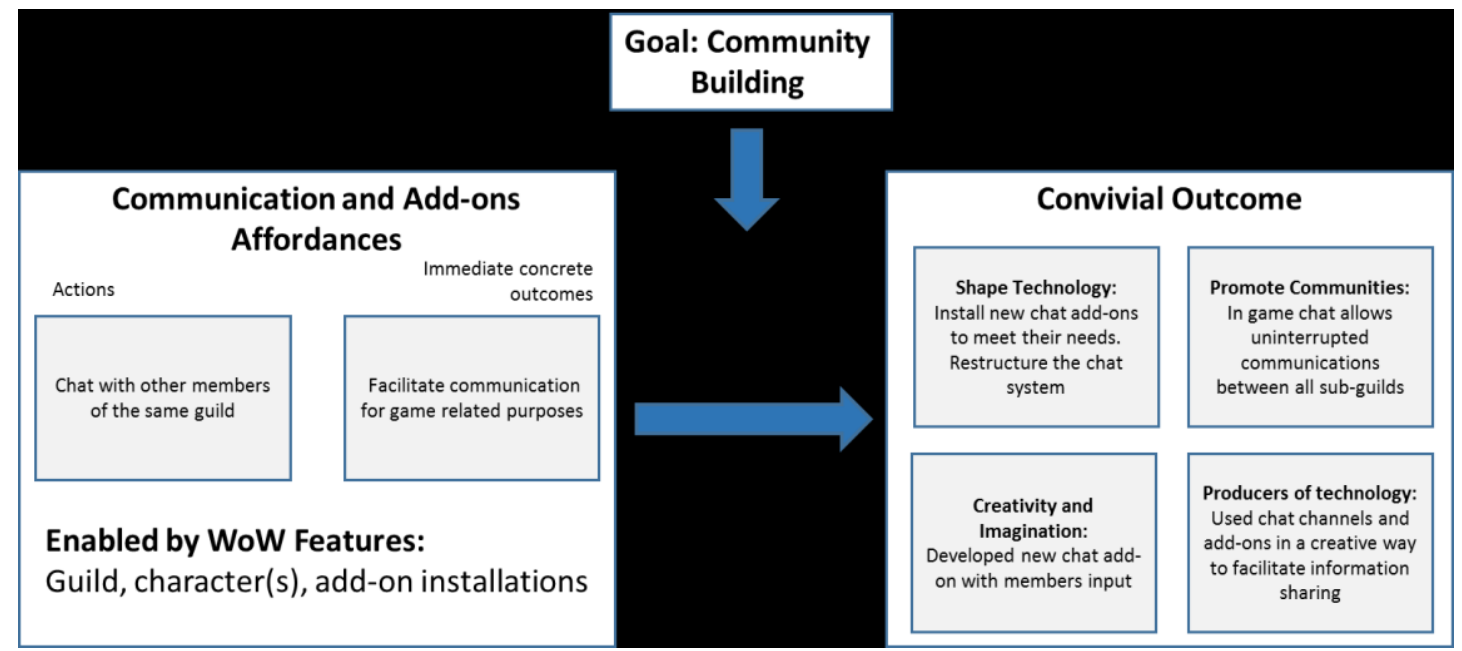

Figure 4: Convivial outcomes of communication for community building 


\subsection{Goal: Periods of Activity}

The periods of activity goal is achieved through the creative combinations of guilds, virtual spaces, and communication affordances.

\subsubsection{Guilds, Virtual Spaces, and Character Movement Affordances}

To create a convivial outcome, Alpha used the affordances which enable character movements around virtual spaces to use the game in a way not initially intended by Blizzard. Similar to physical world LGBT movements, Alpha periodically holds events. For the time that the researcher was involved with Alpha, they held an annual pride parade inside the game. The parade was attended by a large number of players (the exact number is only available to Blizzard). The parades enabled Alpha to shape the usage of WoW beyond its original design intentions, by using the character movement affordance, but on a larger scale with thousands of players performing the same affordance simultaneously. The researcher used Thirl to participate in the parade alongside the other Alpha members. At the end of the parade, various other activities took place such as a model competition named "Azeroth's Next Top Model". For an example of a video screen cam of a pride parade and dance party within WoW which was created by the researcher, see this YouTube link: https://youtu.be/Vfko_sN5z40.

The activities afforded by WoW enable the members of Alpha to shape the use of the technology for their movement goals. For example, the virtual spaces are used for exploration and other gaming activities during regular gameplay. However, Alpha uses this affordance in these virtual spaces by hosting the pride parades and dance parties, involving the creativity and imagination of many Alpha members to create a successful event. Additionally, for these activities, many players change the gender of their character temporarily (like appearing in drag in the physical world). WoW affords any player to change their gender for a \$15 (USD) fee, allowing Alpha to shape the technology more into line with physical world pride parades which commonly have drag acts.

Member: I even performed a little "gender reassignment" on <my character name> this last week to show some love for my lady members. [Shape Technology; Creativity and Imagination]

Just as physical world pride parades have floats, Alpha creates virtual floats (figure 5). Members often post announcements advertising for other members to join the floats. 
However, due to the limited affordances of WoW (compared with the physical world), members cannot construct large floats to travel on. Therefore, they tend to have floats around game related items or themes. For example, the announcement below asks any member who has a 'Mechano-hog' (a bike) to ride together.

Member: Got a Mechano-hog? Want to lead off the Pride parade while riding it? Then this is the float for you! Most of us probably know that Real Life pride parades are traditionally led by Dykes on Bikes. We in Alpha are open to all genders on bikes - bring your hog, find a friend to ride with you if you'd like, and rev your engine as we head to Booty Bay! [Shape the Technology; Creativity and Imagination]

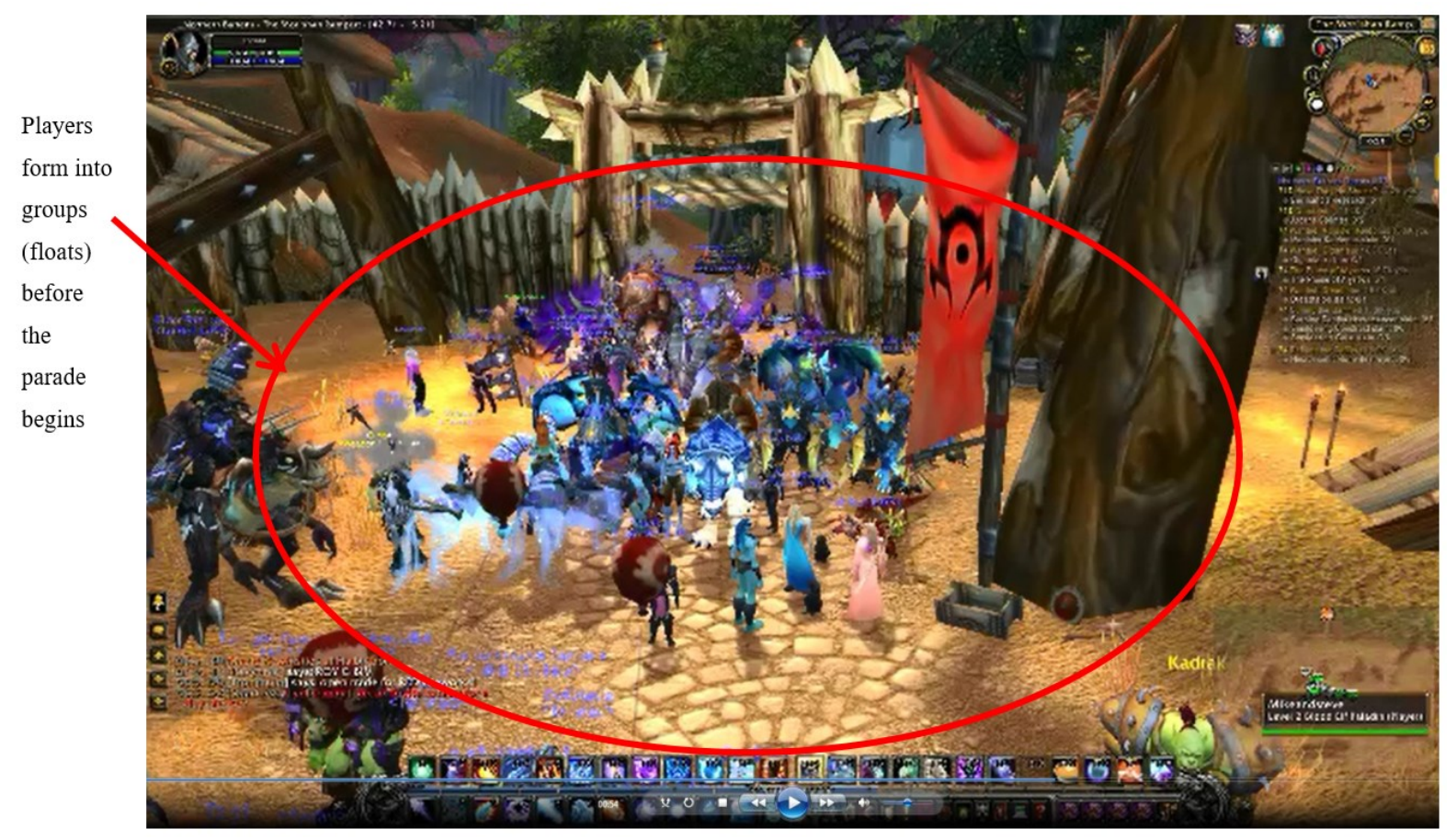

Figure 5. Alpha members are getting ready to start the parade and forming floats. [Shape Technology; Creativity and Imagination; Promote Communities; Producers of Technology $]^{1}$

For ordinary gameplay, players have spells they can use in battle against other players which affords gameplay. These spells, called Area of Effect (AoE), can be used for a different

\footnotetext{
${ }^{1}$ This image, and all subsequent images are screenshots of WoW, and have the following copyright statement: (C)2010 Blizzard Entertainment, Inc. All rights reserved. Cataclysm is a trademark, and World of Warcraft, Warcraft and Blizzard Entertainment are trademarks or registered trademarks of Blizzard Entertainment, Inc. in the U.S. and/or other countries.
} 
purpose for Alpha members during the parade and dance party to create lighting and sparkling effects. However, the use of AoE caused an unintended consequence. The Alpha leadership became aware that one potential impact of using spells was increased server and CPU usage. The Alpha leadership proposed to members that the use of AoE be limited and kept to a minimum. Most members agreed to follow these guidelines and adjusted their parade behaviour accordingly. During the parade, members get on a boat and travel to another zone. However, in past years, due to the increased number of parade participants, the technical features which implement the boat disappeared, and they were unable to use it.

Alpha Founder: Please cease all AoE and other types of eye bling. We traditionally have crashed the boat due to our lag largeness, and avoiding excessive visuals helps those of us with older/crappier CPUs. [Shape Technology]

Another unique aspect of Alpha not used in ordinary gameplay is that during the parade, Alpha's sister group from the opposing in-game faction also participates in the parade. In a gaming sense, players on the opposing faction are enemies. However, during the parade, these two opposing guilds come together and march in the parade side by side. WoW is a game designed to kill your enemies on the opposing faction, although during the parade, Alpha and its sister guild declare a temporary amnesty and members of both guilds are asked not to participate in fighting (called Player vs Player, or PvP). If any members of both guilds fight during the parade, the leaders may expel the players from the parade. It is also common for other players who are not members of either guild to come and watch the parade (Figure 6), creating awareness of LGBT issues beyond the gaming world. However, because occasionally some protesters show up, Alpha announced the following rules for the parades:

Alpha founder: \#1. No PVP! At all, please. We will be marching nuts-to-butts with our co-host guild, as well as many other Alliance members. If you see PvP actives trying to engage, please avoid and ask for an officer in guild chat. \#2. Griefers and "protesters" have shown up in increasing (but still small) numbers in recent years. This is how you know this event is the shiznit, when people protest it. Screw 'em, ignore 'em, and kindly re-read rule \#1. [Promote Communities; Producers of Technology; Shape Technology] 
Additionally, the guild structure afforded by WoW allows for Alpha to create temporary guilds for non-members to participate in the parade, meaning that non-members would be able to participate in the Alpha chat during the parade. The temporary guild is then closed after the parade.

Officer: We are encouraging you to invite friends from other guilds, other servers, and friends who've never played WoW before. We're using our old guest guild [Tots] this year. [Promote Communities]

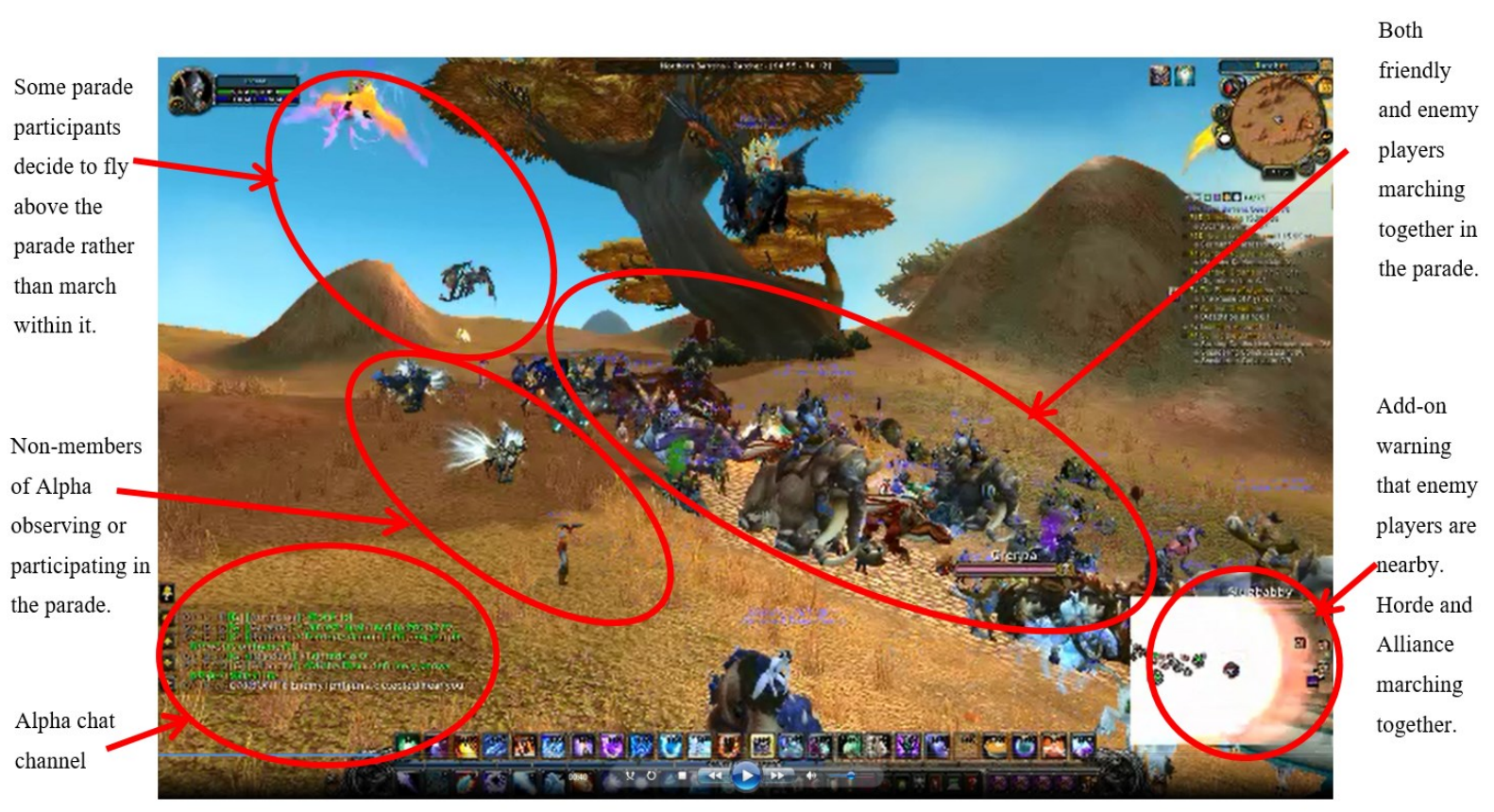

Figure 6. Virtual Pride Parade. [Shape Technology; Creativity and Imagination; Promote Communities; Producers of Technology].

However, as a precaution, Alpha sets up what they call 'Parade Security' to take care of any issues that may arise during the parade, including protesters, and protecting low-level characters who join the parade.

Alpha Founder: Plans for the 5th Annual Pride Parade are already in the works. I'm asking members of War Alpha to hollah out to volunteer to work security for the event. What this would entail is dressing all intimidating ninja-black and space ourselves out along the parade route, duties being: 1. We generally get 'guests' from other servers that roll a level one on the day of the event. These folks as well as low- 
level Alpha members may need some protecting from random red mobs along the parade path. 2. We'll especially need high-level War Alphas to bring up the rear for these and other low-level un-mounted friends. 3. Spam /s reminders about staying 'PVP free' when we meet our Alliance friends outside Crossroads. 4. Help arrange warlock summons or mage portal or whatever is needed for stranded folks if necessary. 5. In the unlikely event that non-Alpha dipshits try to crash the party with

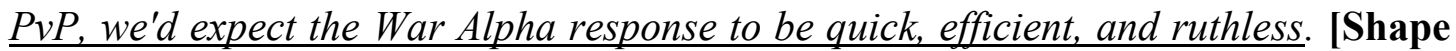
Technology; Creativity and Imagination; Promote Communities; Producers of Technology].

The parades take place in several virtual spaces afforded by WoW. Alpha uses the virtual space in a different way than the intentions of the game designers, for the pride parades. Figure 7 illustrates how the virtual space supports the pride parade events attended by thousands of characters, by illustrating it next to the same virtual space once the parade has finished.
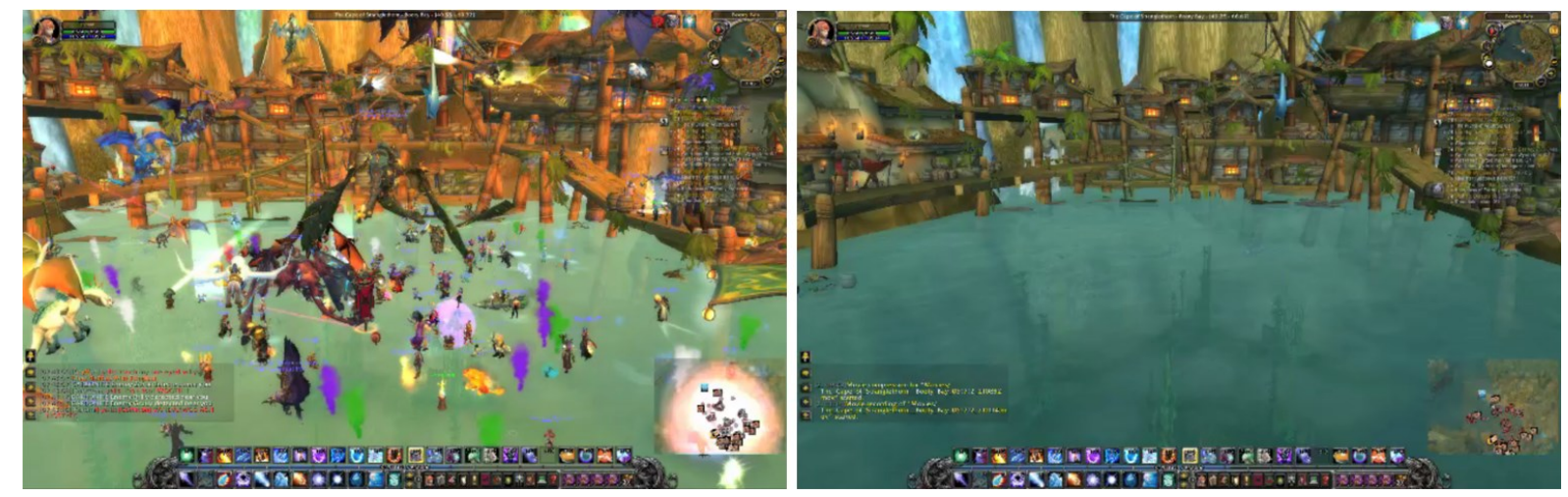

Figure 7: parade event and avatars (left) vs virtual location once the event finished (right).

[Shape Technology; Creativity and Imagination; Promote Communities; Producers of Technology].

Alpha used the affordances of guilds, virtual spaces, and player movements to use the game in a way that was not initially intended by the game designers, e.g. through pride parades (Figure 8). 


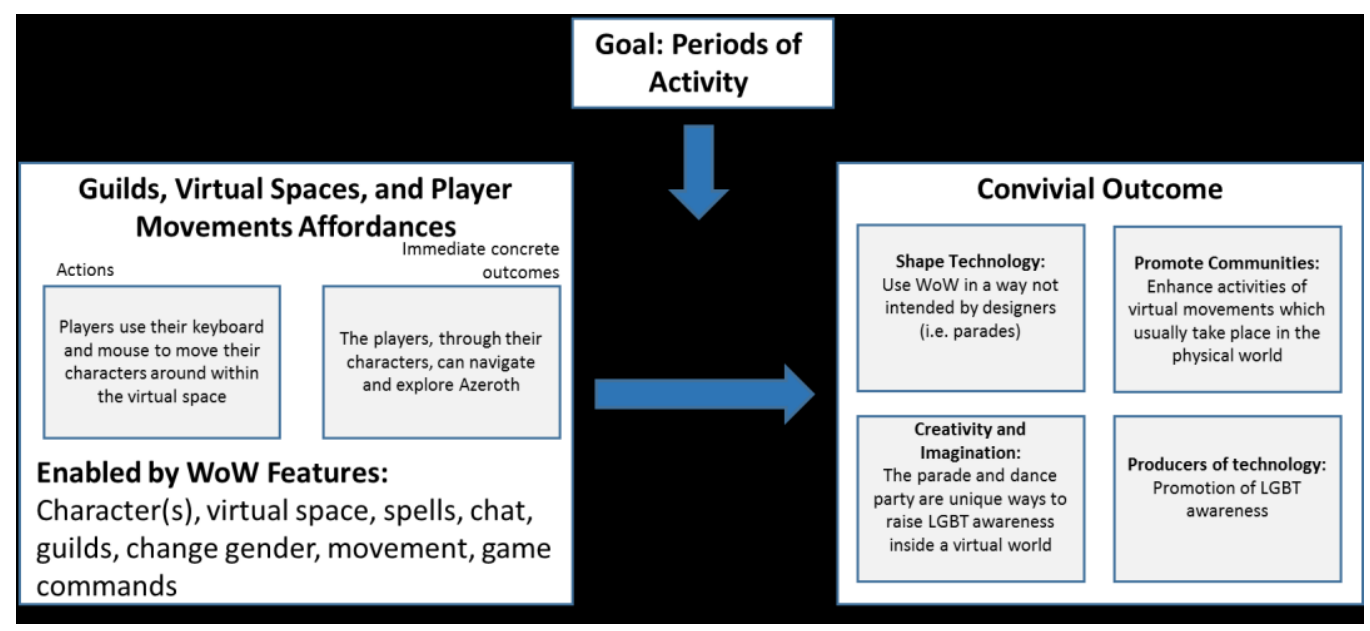

Figure 8: Convivial outcomes of parades and dance party for periods of activity

\subsubsection{Virtual Spaces and Character Movements Affordances}

Virtual spaces and character movements can change as Blizzard implements new patches and changes the implementation of the game. The parades were significantly impacted when Patch 4.0.3a (November 2010), nicknamed 'The Shattering', was implemented. The virtual environment was drastically changed after the patch was implemented. The dragon Deathwing caused some areas of Azeroth to form giant canyons, others were flooded, while volcanoes appeared in some areas (figure 9). Before this patch, the pride parade began at a small village called Camp Taurajo in the zone of Azeroth known as The Barrens, which was flat plain land. The participants then marched towards a town called Ratchet (a new and old route map is provided in figure 10). From here, the participants boarded a boat which took them to a portside town known as Booty Bay on the other side of the ocean (although the journey across the ocean only takes about a minute in game time). When patch 4.0.3a was implemented, Alpha could no longer parade through The Barrens as this was the location of the new canyon with lava flowing at its base which is not crossable. Camp Taurajo, the starting location of the parade, was also destroyed. Alpha was forced to choose a new parade route in order to continue to hold the parades, which also represents that affordances can be constraining as well as enabling. 

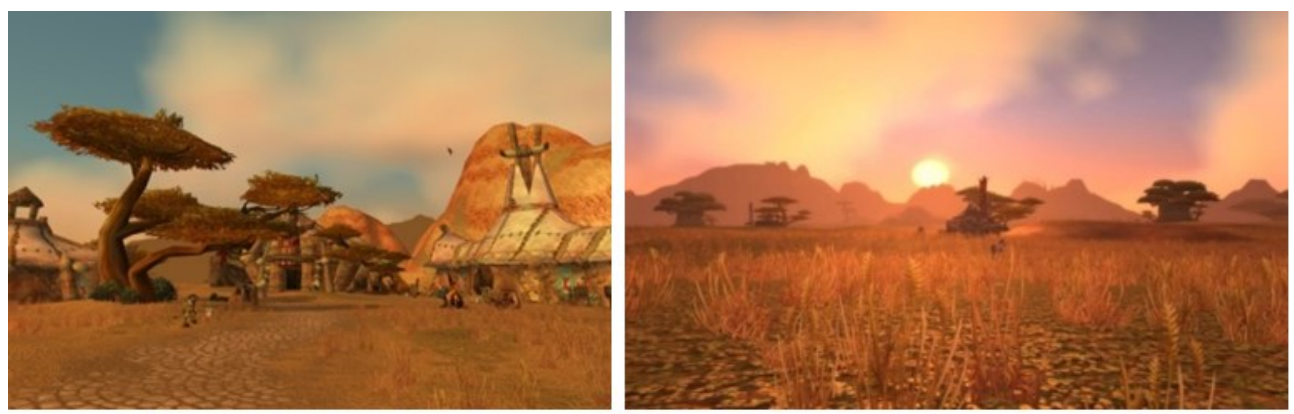

Flat plain land

affords safe location

to begin and to march

in the parade
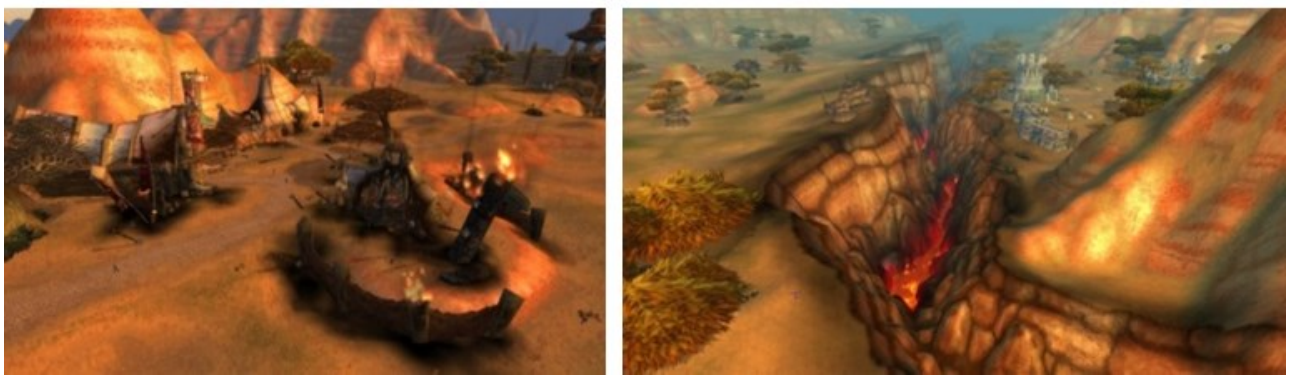

Destroyed village

and new canyon

destroy the

affordance of

marching

Figure 9. Parade starting location before patch (top-left), parade route before patch (top-right), parade starting position after patch (bottom-left), parade route after patch (bottom-right).

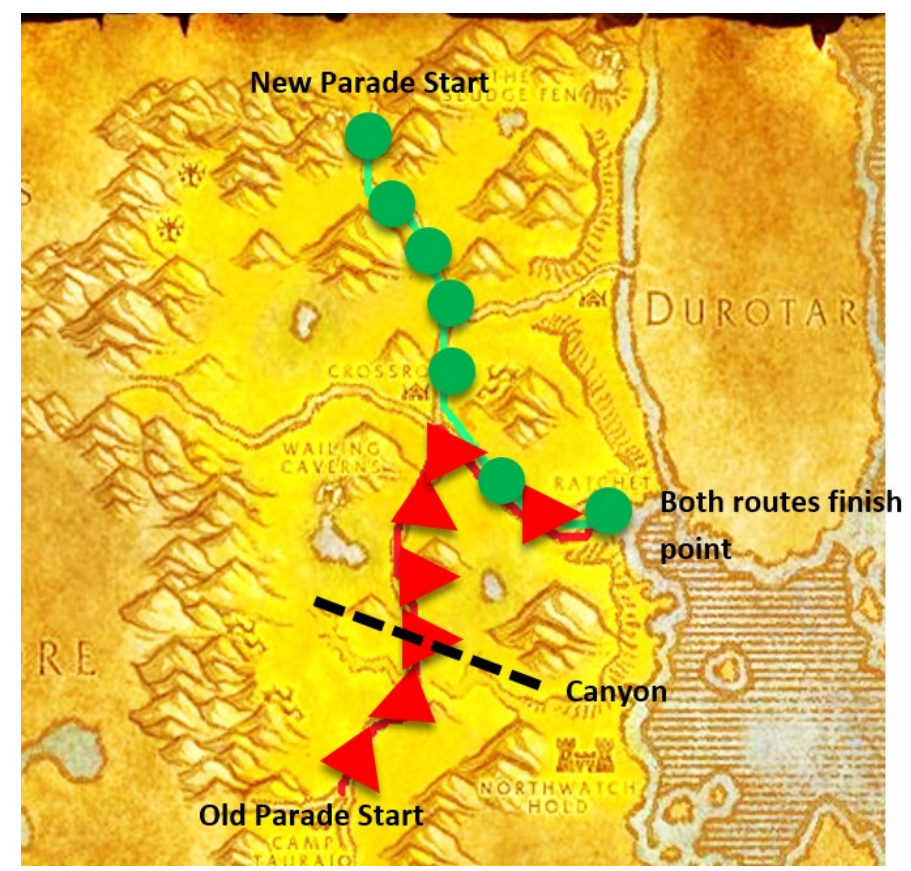

Figure 10: Old parade route (triangles), new parade route (circles). [Shape Technology; Creativity and Imagination; Promote Communities; Producers of Technology]

Parades are a method of expressiveness for social movements. Therefore Alpha was keen for this event to continue. Alpha put much effort into choosing a new parade route, which also came with some excitement, illustrating how Alpha was able to adapt to the changing virtual space affordance and create an alternative convivial outcome. Alpha knew in 
advance of the parade in 2010 that it would be the last time at the location, as the release date of The Shattering patch was well known.

The leaders discussed and agreed on a new parade route with a consultation with their sister guild. For the 2011 parade, an entirely new parade route was used. All Alpha members were informed of the new route before the parade took place. The new starting point was a small village known as Mor'shan Rampart. The parade then marched towards a village known as The Crossroads, where they met up with the sister guild. Both guilds then marched together towards Ratchet, before taking the boat to Booty Bay. Based on the changing virtual spaces affordance, Alpha was able to adapt their periods of activity to decide on new parade routes (figure 11).

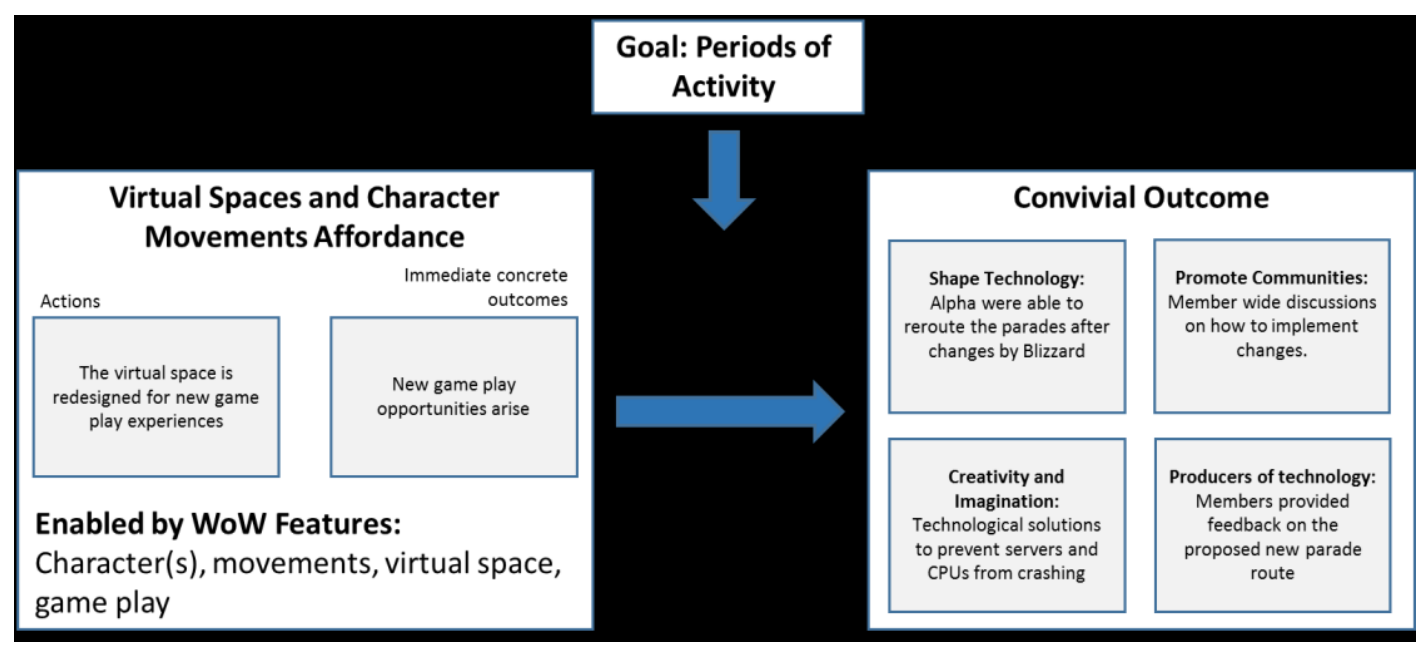

Figure 11: Convivial outcomes of virtual spaces for periods of activity

\section{DISCUSSION}

Convivial outcomes are desired states. However, the mechanisms on how to achieve these were lacking in the literature. To address this gap, this paper proposed that affordances are necessary to understand the socio-technical nature of creating convivial outcomes. This paper introduces the concept of convivial affordances, which builds on connective affordances (Vaast et al., 2017), and social affordances (Zheng \& Yu, 2016).

\subsection{Theoretical Implications: Convivial Affordances}

Despite the control that game companies have over virtual worlds (Roquilly, 2011), this paper illustrated that social movements could exploit affordances of virtual worlds to create a convivial outcome which enables online social movements to use them for their specific 
goals and desires (Community Building, and Periods of Activity). Based on the findings, we were able to create convivial affordances in figure 12 .

Convivial affordances bring together the theories of affordances and convivial tools and suggest a process to enable social users to shape IT artefacts, through a creative combination of affordances for their specific needs. Convivial affordances are based on the shared patterns of feature use and emerging roles of connective affordances (Vaast et al., 2017), and the social practices within the collective action processes of social affordances (Zheng \& $\mathrm{Yu}$, 2016). Convivial affordances are enacted through the shared goals of social users, and community involvement.

The use of convivial affordances relies on existing functional affordances. The first step is the interpretation of existing affordances. Affordances are designed and written into IT artefacts (Grint \& Woolgar, 1997; Hutchby, 2001), and should be understandable to users (Norman, 1999). However, for convivial affordances, existing affordances are interpreted (Hutchby, 2001), and combined in creative ways, through the specific goals of social users and community involvement. Therefore, they draw on the idea of connective affordances and the interdependence of users (Vaast et al., 2017), but differ in that goals are collectively determined. The goals in our study developed from several areas. For example, social movements often seek new social spaces (Johnston et al., 1994), and LGBT members of society often come together as a community (Lloyd, 2002; Savage et al., 2005) to overcome threats (Baumeister \& Vohs, 2007).

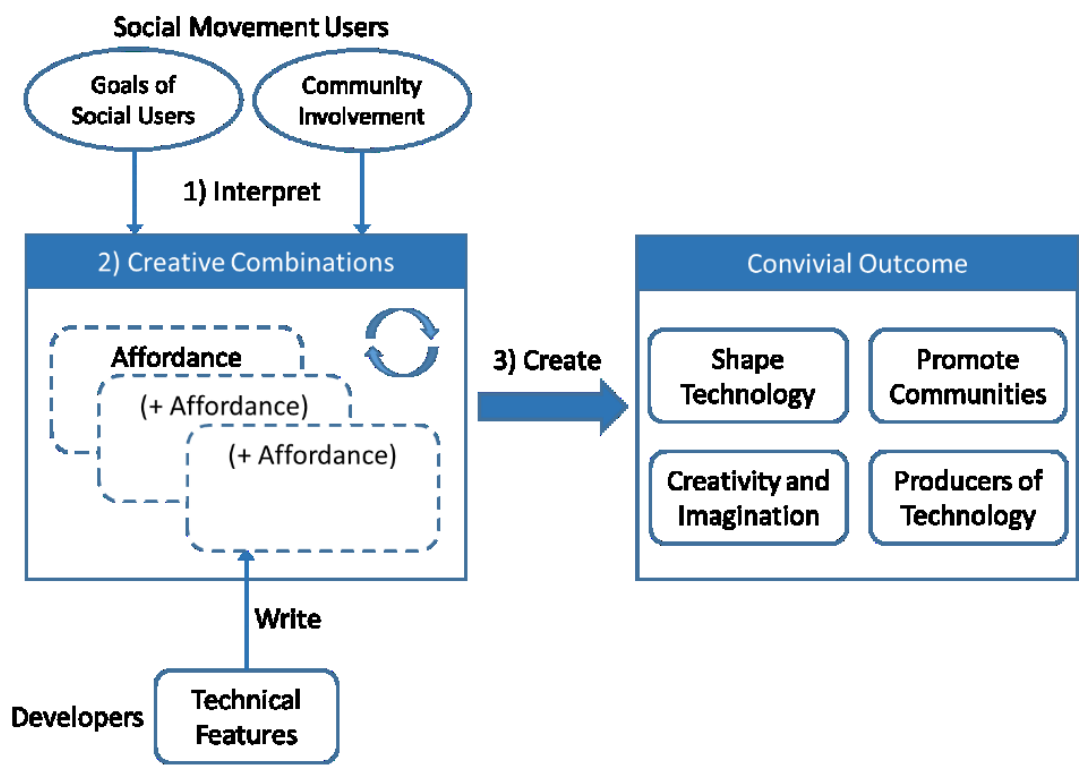

Figure 12: Convivial affordances 
Tim et al. (2018) argue that affordances lead to collective outcomes and goals. For convivial affordances, the goals are determined before the affordances are used, which enables a greater sense of community involvement and shared goals. The second step enables social users to creatively combine multiple existing affordances for their desired use of the IT artefact. These combinations of affordances are based on the social practices performed within the collective action process of the online social movement (Zheng \& Yu, 2016). Therefore, their usage of the IT artefact will be entirely different compared with that of other users with different goals (the example of ordinary gameplay in this study).

The final step is to use this creative combination of affordances to create a convivial outcome. Previous research has argued for immediate concrete outcomes of affordances (Strong et al., 2014). Our findings suggest that the outcomes of convivial affordances are less immediate, and may develop and evolve over time. This gradual creation of a convivial affordance may be hampered by the on-going development of the IT artefact, creating adaptions to convivial outcomes as social users seek new convivial affordances. For example: as new patches are implemented, the design of WoW evolves, which forced Alpha to change its use or combinations of affordances, which ultimately changes how Alpha can use convivial affordances to create convivial outcomes. Therefore, we argue that using convivial affordances creates outcomes that are more dynamic than immediate concrete outcomes.

The focus on the goals of specific users for convivial affordances developed from the ideas of (Illich, 1973)'s definition of conviviality: tools "can be easily used, by anybody, as often or as seldom as desired, for the accomplishment of a purpose chosen by the user" ( $\mathrm{p}$. 22), which suggests that users can use the technology as they please. Missing from this definition is the affordance lens. It is affordances which enable users to achieve specific outcomes (Hutchby, 2001, 2003). However, goals of users may differ, and for an online social movement, these goals are collectively determined (Staggenborg, 2011) through community involvement. In this paper, we have discovered that changes in technology force the user to redefine their use of affordances in order to continue using the technology for their goals. It is these practices we have suggested are convivial affordances, and that to understand the creation of convivial outcomes, we must also consider both the goals and affordances. A summary of convivial affordances is provided in table 1. 


\begin{tabular}{|l|l|}
\hline Users & Online communities \\
\hline Goals & Collectively determined and community involvement \\
\hline Affordances & $\begin{array}{l}\text { Existing affordances are creatively combined and iteratively updated. } \\
\text { Connective affordances - interdependence of users, emerging roles } \\
\text { Social affordances - social practices through collective action }\end{array}$ \\
\hline Outcomes & Less immediate, dynamic, and may change over time \\
\hline
\end{tabular}

Table 1: Summary of convivial affordances

\subsection{Theoretical Implications: Online Social Movements}

Another theoretical contribution of this paper is the creation of a new theoretical tool for understanding online social movements. According to Hara and Huang (2011), we need better theoretical approaches to conceptualise the interactions among technology, social movement users, and their environments. The concept of convivial affordances can be used to understand how movement members exploit affordances for their desired convivial outcomes. For example, a re-analysis the blogging campaigns in Iran (Ameripour et al., 2010) using convivial affordances might provide new insights on the role technology places in online social movements.

Previous research has examined how conviviality is considered during systems development through involvement with users (Johri \& Pal, 2012). However, in systems such as online games, the game is already developed and live for users. Therefore, online social movement members must create convivial outcomes for themselves through the use of affordances. Concerning the convivial concept, shaping the technology, it is evident that the creative use of affordances allowed for the technology to be used beyond Blizzard's initial designs. The affordances available to Alpha allowed them to come together to shape the technology for their specific use. Virtual worlds are created by a team of designers and developers who create elaborate storylines for players. As was illustrated in this study, some portions of that design may cause issues for social movements. However, it would not be possible for Blizzard to redesign parts of the game for different cultural groups or minorities, as suggested by Zhou et al. (2015). Therefore, to create the convivial outcomes desired by Alpha, they were able to creatively combine affordances usually used for ordinary gameplay, to create alternative outcomes based on their desires.

Over time, convivial outcomes arose, and discriminatory practices by other players reduced, and the server Alpha is based on became well known throughout WoW. Griefing (Chesney, Coyne, Logan, \& Madden, 2009) towards LGBT members became frowned upon 
by most users, relating to the convivial concept, promotion of communities, as convivial affordances allow communication among members of the greater player community. High levels of communication from Alpha leaders and members help in the continuation of the social movement (Staggenborg, 2011), which was evident during the challenges that Alpha faced when Blizzard imposed technological changes on them. Convivial affordances enabled them to maintain a strong community.

Online social movements have periods of activity and have similarities and differences to physical world social movements. Alpha uses the affordances of guilds, virtual spaces, and character movements to hold regular events such as the pride parade which brings people together (promotion of communities), as well as making the most of the energy of individuals to encourage creativity in the ways in which the parades are implemented (creativity and imagination). Therefore, Alpha was able to use convivial affordances to create similar periods of activity to the physical world, for example, a virtual protest (Blodgett, 2009; Blodgett \& Tapia, 2010; Robinson, 2008). Social movements often show highly dramatic forms of demonstration (Tarrow, 1994). The convivial affordances allowed members to express themselves in ways not possible in the physical world, such as gender swapping (Boellstorff, 2008) or using spells (an affordance provided by WoW) as lighting effects.

Membership of virtual world social movements is highly influenced by the technological requirements of the virtual world, and platform stability (Mueller, Hutter, Fueller, \& Matzler, 2011). As we have seen, the size of the LGBT movement was impacted by changes made by Blizzard. As a result of these changes, Alpha was forced to reconsider their use of the guilds and membership affordances creatively and was able to reorganise, which is quite different from physical world social movements that have no technological requirements constraining their actions. Castronova (2005) and Roquilly (2011) argue that the designers of virtual worlds are gods and users of these worlds must follow whatever decisions they make. Physical world social movements have periods of growth and decline as individual members join and leave movements (Staggenborg, 2011), and changes made by designers may force a virtual world movement to decline prematurely. However, Alpha was able to overcome some of the technological limitations imposed by Blizzard, which enabled individual members to remain in the movement. However, this process took a lot of time and energy from the leaders of Alpha, and through their engagements with Alpha members.

Concerning the convivial concept, producers of technology, Alpha used the affordances of add-ons (Taylor, 2008) and membership to enable communication between all 
of the Alpha sub-guilds. Virtual worlds allow for knowledge creation (Mueller et al., 2011) and information flows (Castronova, 2005). Social movements often have to share knowledge around strategies, organisational structures, and money (Edwards \& McCarthy, 2003). Alpha was able to use these goals of community building to bring together know-how and ideas from members about the upcoming changes to WoW. They are also able to use the technical skills of some Alpha members to develop the new chat add on.

Social movements often deal with injustice (Staggenborg, 2011), and in this case, they felt very strongly that Blizzard was damaging their ability to stay together as a group. Roquilly (2011) argued how game companies control over the virtual worlds they create. However, as we saw, Alpha was able to deal with multiple challenges to the changes in WoW imposed by Blizzard. NSMs often question authorities which limit citizen input, (Pichardo, 1997), and in this case, Blizzard initially did not listen to their concerns, and therefore they had to find the solution for themselves. Therefore, they were able to adapt the affordances beyond decisions initially made by the designers for their own needs.

Togetherness is an important aspect of social movements (Goodwin \& Jasper, 2003), and this is also true in virtual world groups (Sherlock, 2007), and profoundly impacts player enjoyment (Nardi \& Harris, 2006). Alpha was able to use the guild affordance to build their movement with a collective identity (Johnston et al., 1994), to create awareness for Alpha issues both inside the virtual world. The affordances used to create the pride parades also allowed this togetherness to be expressed (Tarrow, 1994). The challenges faced by the guild size caps only reinforced how they wanted to stay together as a group despite the technological changes happening around them. Chat is also a virtual world affordance which enables virtual world users to share information (Nardi, Ly, \& Harris, 2007), and Alpha was successful in adapting the communications affordances to meet their needs.

Recruiting members is very important for social movements (McCarthy \& Zald, 1977). Most of the time, social movements come together for a common grievance (Staggenborg, 2011) and consist of a collective identity (Johnston et al., 1994). Lee (2014) discussed users revealing their true identities in virtual worlds. Alpha members were very open about their sexual identity and used the affordances of membership and add-ons to create $\mathrm{n} 2 \mathrm{f}$, where members could see photos of other members' in-game.

The changes to the game created challenges for Alpha and had the potential to fragment the movement. They were able to get around this fragmentation through the addition of the new inter-guild chat, which gave the appearance of connected guilds, although 
technically they were separate. Blizzard can act in a totalitarian manner in that it imposes its designs on the player population (Roquilly, 2011). However, as was shown in the case study, Alpha was able to make the appropriate changes by using convivial affordances to enable their structure, recruitment, methods of expressiveness (Scott, 1990), and communications (Blodgett \& Tapia, 2010) to continue to exist.

\subsection{Practical Implications}

This study provides some practical examples of how virtual worlds can act as a safe haven for the LGBT community (Cabiria, 2008), or create awareness for LGBT issues within a broader gaming community. However, there are other types of users of virtual worlds. For example, virtual worlds have some important implications for business as new forms of organising emerge. For example, Greenpeace has protested the killing of penguins within WoW. These findings could shed some light on the issues faced when operating within virtual worlds, and suggests that organisations need to be willing to evolve if they want to continue operating in these virtual environments.

This paper also raised some important issues for virtual world social movements. If a social movement wants to use virtual worlds to advance its cause, it is necessary for the movement to be aware of virtual world affordances which they could use to their advantage, or be aware of affordances which could potentially be a hindrance to their cause. Social movements also need to be aware of the type of virtual world they might use, i.e. a social virtual world, or a gaming virtual world, as depending on the type, different limitations or affordances might impact the movement.

We are also aware of other uses of WoW. For example, there is a regular event called 'Running of the Gnomes' used to raise awareness for breast cancer. In 2008, there was a political rally in WoW for then-(USA) presidential candidate Ron Paul. The findings from this research could provide further insights into future events like these. In the future, Social movements may make use of other emerging technologies, such as virtual reality or augmented reality. Insights from this study could provide the analytical tools necessary to understand how different technologies impact LGBT movements or other social movements. 


\section{CONCLUSION}

This paper has demonstrated that convivial affordances can be used to create desired outcomes for online social movements, based on their goals and desires, and community involvement. This paper took the position that an understanding of affordances is required for users to be able to create convivial outcomes, thus creating the concept of convivial affordances. This study suggests that the design of IT artefacts constrain users, but users are still able to shape their usage by creatively combining affordances for their own goals and desires. Different online communities could also use convivial affordances, and different technologies, with different goals and desires, to determine convivial outcomes. For example, the Me Too movement (a movement against sexual harassment and sexual assault) spread globally through social media with the hashtag \#MeToo. An analysis of this movement through the lens of convivial affordances could provide insights on how the campaign used social media to grow and sustain its message to a global audience.

This study has some limitations. Firstly, the study is based on one ethnographic study with an in-depth understanding of one social movement in WoW which is a common criticism of ethnographic research. However, Myers (2013) argues that just as researchers can generalise from one case study to theory (Walsham, 1995), it is also possible to generalise from one ethnography to theory. To mitigate some of these concerns, Alpha's goals were compared against the goals of ordinary game-play. Future studies can also examine other social phenomena or technologies such as virtual reality which is becoming ever popular. The data set for this study consisted mostly of data collected from online sources (except for informal conversations with WoW players). A future study could conduct other primary data collection techniques to validate the theoretical framework, which could be achieved by making comparisons with other communities in WoW and observing differences and similarities with Alpha. Lastly, Blizzard refused to participate in this study, but this is a common issue faced by other researchers (e.g. Nardi, 2010). We do not see this as a problem, as the concept of conviviality relates to the usage of technology in accordance with a user's intentions and is independent of specialists.

\section{REFERENCES}

Adam, B., Duyvendak, J. W., \& Krouwel, A. (1999). Introduction. In B. Adam, J. W. Duyvendak, \& A. Krouwel (Eds.), The Global Emergence of Gay and Lesbian 
Politics: National Imprints of a Worldwide Movement (pp. 1-11). Philadelphia: Temple University Press.

Ameripour, A., Nicholson, B., \& Newman, M. (2010). Conviviality of Internet social networks: An exploratory study of Internet campaigns in Iran. Journal of Information Technology, 25(2), 244-257.

Ashford, C. (2009). Queer theory, cyber-ethnographies and researching online sex environments. Information \& Communications Technology Law, 18(3), 297-314.

Baumeister, R. F., \& Vohs, K. D. (2007). Encyclopedia of social psychology. Thousand Oaks: Sage Publications.

Benbasat, I., \& Zmud, R. W. (2003). The Identity Crisis within the IS Discipline: Defining and Communicating the Discipline's Core Properties. MIS Quarterly, 27(2), 183-194.

Benford, R. D., \& Snow, D. A. (2000). Framing processes and social movements: An overview and assessment. Annual Review of Sociology, 26(1), 611-639.

Blodgett, B. M. (2009). And the ringleaders were banned: an examination of protest in virtual worlds. Paper presented at the Proceedings of the fourth international conference on Communities and technologies, University Park, PA, USA.

Blodgett, B. M., \& Tapia, A. H. (2010). When Protests go Virtual: How Organizing Social Protest in Virtual Worlds Changes the Nature of Organizing. Paper presented at the Proceedings of the Sixteenth Americas Conference on Information Systems (AMCIS), Lima, Peru.

Blodgett, B. M., \& Tapia, A. H. (2011). Do avatars dream of electronic picket lines?: The blurring of work and play in virtual environments. Information Technology \& People, 24(1), 26-45.

Boellstorff, T. (2008). Coming of Age in Second Life. Princeton, New Jersey: Princeton University Press.

Bradley, K. (2016). Bike Kitchens - Spaces for convivial tools. Journal of Cleaner Production, In Press, 1-8.

Braithwaite, A. (2018). WoWing alone: The evolution of "multiplayer" in World of Warcraft. Games and Culture, 13(2), 119-135.

Brignall, T. W., \& VanValey, T. L. (2007). An Online Community as a New Tribalism: The World of Warcraft. Paper presented at the Proceedings of the 40th Annual Hawaii International Conference on System Sciences. 
Brunsting, S., \& Postmes, T. (2002). Social Movement Participation in the Digital Age : Predicting Offline and Online Collective Action. Small Group Research, 33(5), 525554.

Buechler, S. M. (1995). New Social Movement Theories. The Sociological Quarterly, 36(3), 441-464.

Cabiria, J. (2008). Virtual World and Real World Permeability: Transference of Positive Benefits for Marginalized Gay and Lesbian Populations. Journal of Virtual Worlds Research, 1(1).

Campbell, J. E. (2004). Getting it on Online: Cyberspace, Gay Male Sexuality, and Embodied Identity. Binghamton, NY: Harrington Park Press.

Cao, J., Basoglu, K. A., Sheng, H., \& Lowry, P. B. (2015). A Systematic Review of Social Networks Research in Information Systems: Building a Foundation for Exciting Future Research. Communications of the Association for Information Systems, 36, 727-758.

Castronova, E. (2005). Synthetic Worlds: The Business and Culture of Online Games: University of Chicago Press.

Castronova, E. (2007). Exodus to the virtual world: how online fun is changing reality. New York, NY: Palgrave Macmillan.

Chemero, A. (2003). An outline of a theory of affordances. Ecological Psychology, 15(2), 181-195.

Chesney, T., Chuah, S.-H., Hui, W., Hoffmann, R., \& Larner, J. (2014). Determinants of friendship in social networking virtual worlds. Communications of the Association for Information Systems, 34(1), 1379-1416.

Chesney, T., Coyne, I., Logan, B., \& Madden, N. (2009). Griefing in virtual worlds: causes, casualties and coping strategies. Information Systems Journal, 19(6), 525-548.

Crenshaw, N., \& Nardi, B. (2016). "It Was More Than Just the Game, It Was the Community": Social Affordances in Online Games. Paper presented at the 49th Hawaii International Conference on System Sciences.

Diaz Andrade, A., Urquhart, C., \& Arthanari, T. S. (2015). Seeing for Understanding: Unlocking the Potential of Visual Research in Information Systems. Journal of the Association for Information Systems, 16(8), 3. 
Durkin, K. F. (2004). The Internet as a milieu for the management of a stigmatized sexual identity. In D. Waskul (Ed.), Net.seXXX: Readings on sex, pornography and the Internet (pp. 131-147). New York: P. Lang.

Edwards, B., \& McCarthy, J. D. (2003). Resources and Social Movement Mobilization. In D. A. Snow, S. A. Soule, \& H. Kriesi (Eds.), The Blackwell Companion to Social Movements. Malden, MA: Blackwell Publishing.

Friedland, J., \& Rogerson, K. (2009). How Political and Social Movements Form on the Internet and How They Change Over Time. Institute for Homeland Security Solutions, November, 1-11.

Garrett, R. K. (2006). Protest in an information society: A review of literature on social movements and new ICTs. Information, Communication \& Society, 9(02), 202-224.

Germov, J., Williams, L., \& Freij, M. (2010). Portrayal of the Slow Food movement in the Australian print media: Conviviality, localism and romanticism. Journal of Sociology, 47(1), 89-106.

Gibson, J. J. (1977). The theory of affordances. In R. E. Shaw \& J. Bransford (Eds.), Perceiving, acting and knowing (pp. 67-82). Hillsdale: Lawrence Erlbaum Associates.

Goel, L., Johnson, N., Junglas, I., \& Ives, B. (2013). Predicting users' return to virtual worlds: a social perspective. Information Systems Journal, 23(1), 35-63.

Goel, L., Johnson, N. A., Junglas, I., \& Ives, B. (2011). From Space to Place: Predicting Users' Intentions to Return to Virtual Worlds. MIS Quarterly, 35(3), 749-771.

Goodwin, J., \& Jasper, J. M. (2003). The Social Movements Reader: Cases and Concepts. In J. Goodwin \& J. M. Jasper (Eds.), The Social Movements Reader. Malden, MA: Blackwell Publishing.

Grgecic, D., Holten, R., \& Rosenkranz, C. (2015). The Impact of functional affordances and symbolic expressions on the formation of beliefs. Journal of the Association for Information Systems, 16(7), 580-607.

Grint, K., \& Woolgar, S. (1997). The machine at work: Technology, work and society. Cambridge: Polity.

Guercini, S., \& Ranfagni, S. (2016). Conviviality behavior in entrepreneurial communities and business networks. Journal of Business Research, 69(2), 770-776.

Hara, N., \& Huang, B. Y. (2011). Online social movements. Annual review of information science and technology, 45(1), 489-522.

Hutchby, I. (2001). Technologies, texts and affordances. Sociology, 35(2), 441-456. 
Hutchby, I. (2003). Affordances and the analysis of technologically mediated interaction: A response to Brian Rappert. Sociology, 37(3), 581-589.

Illich, I. (1973). Tools for Conviviality. New York: Harper Collins.

Johnston, H., Laraña, E., \& Gusfield, J. R. (1994). Identities, Grievances, and New Social Movements. In E. Laraña, H. Johnston, \& J. R. Gusfield (Eds.), New Social Movements: From Ideology to Identity (pp. 3-35). Philadelphia: Temple University Press.

Johri, A., \& Pal, J. (2012). Capable and convivial design (CCD): a framework for designing information and communication technologies for human development. Information Technology for Development, 18(1), 61-75.

Kim, J. w., Kim, Y., \& Yoo, J. J.-s. (2014). The public as active agents in social movement: Facebook and Gangjeong movement. Computers in Human Behavior, 37, 144-151.

Klein, H., \& Myers, M. (1999). A Set of Principles for Conducting and Evaluating Interpretive Field Studies in Information Systems. MIS Quarterly, 23(1), 67-93.

Kling, R., Rosenbaum, H., \& Sawyer, S. (2005). Understanding and Communicating Social Informatics: A Framework for Studying and Teaching the Human Contexts of Information and Communication Technologies. New Jersey: Information Today, Inc.

Kozinets, R. V. (2010). Netnography. Doing Ethnographic Research Online. London: Sage Publications Ltd.

Kreps, D. (2013). Performing the Discourse of Sexuality Online. In W. Steven \& H. Stylianos (Eds.), Digital Identity and Social Media (pp. 118-132). Hershey, PA, USA: IGI Global.

Lee, J.-E. R. (2014). Does virtual diversity matter?: Effects of avatar-based diversity representation on willingness to express offline racial identity and avatar customization. Computers in Human Behavior, 36, 190-197.

Leizerov, S. (2000). Privacy Advocacy Groups Versus Intel : A Case Study of How Social Movements Are Tactically Using the Internet to Fight Corporations. Social Science Computer Review, 18(4), 461-483.

Leonardi, P. M. (2013). When Does Technology Use Enable Network Change in Organizations? A Comparative Study of Feature Use and Shared Affordances. MIS Quarterly, 37(3), 749-775. 
Lloyd, S. (2002). Pleasing spectacles and elegant dinners: Conviviality, benevolence, and charity anniversaries in eighteenth-century London. The Journal of British Studies, 41(01), 23-57.

MacCartney, D. (2018). The Global-Local Tension of LGBT Rights. Human Rights Review, 19(1), 121-126.

Majchrzak, A., Faraj, S., Kane, G. C., \& Azad, B. (2013). The contradictory influence of social media affordances on online communal knowledge sharing. Journal of Computer - Mediated Communication, 19(1), 38-55.

Majchrzak, A., \& Markus, M. L. (2012). Technology affordances and constraints in Management Information Systems (MIS) Encyclopedia of management theory. Thosand Oaks: Sage Publications.

Majchrzak, A., Markus, M. L., \& Wareham, J. (2016). Designing for Digital Transformation: Lessons for Information Systems Research from the Study of ICT and Societal Challenges. MIS Quarterly, 40(2), 267-277.

Maki, J. L. (2017). Gay subculture identification: Training counselors to work with gay men. Vistas Online.

Mansour, O., Askenäs, L., \& Ghazawneh, A. (2013). Social media and organizing: an empirical analysis of the role of wiki affordances in organizing practices. Paper presented at the International Conference on Information Systems (ICIS).

Markus, M. L., \& Silver, M. S. (2008). A foundation for the study of IT effects: A new look at DeSanctis and Poole's concepts of structural features and spirit. Journal of the Association for Information Systems, 9(10/11), 609-632.

Martončik, M., \& Lokša, J. (2016). Do World of Warcraft (MMORPG) players experience less loneliness and social anxiety in online world (virtual environment) than in real world (offline)? Computers in Human Behavior, 56, 127-134.

McCarthy, J. D., \& Zald, M. N. (1977). Resource Mobilization and Social Movements: A Partial Theory. The American Journal of Sociology, 82(6), 1212-1241.

McKenna, B., Gardner, L. A., \& Myers, M. D. (2010). Chaotic Worlds: An Analysis of World of Warcraft. Paper presented at the Americas Conference on Information Systems (AMCIS), Lima, Peru.

McKenna, B., Myers, M. D., \& Newman, M. (2017). Social media in qualitative research: Challenges and recommendations. Information and Organization, 27(2), 87-99. 
Miranda, S. M., Young, A., \& Yetgin, E. (2016). Are social media emancipatory or hegemonic? Societal effects of mass media digitization. MIS Quarterly, 40(2), 303329.

Mowlabocus, S. (2010). Gaydar Culture: Gay Men, Technology and Embodiment in the Digital Age. Burlington: Ashgate.

Mueller, J., Hutter, K., Fueller, J., \& Matzler, K. (2011). Virtual worlds as knowledge management platform - a practice - perspective. Information Systems Journal, 21(6), 479-501.

Myers, M. D. (2013). Qualitative Research in Business \& Management (2nd ed.): Sage Publications London.

Myers, M. D., \& Newman, M. (2007). The Qualitative Interview in Is Research: Examining the Craft. Information and Organization, 17(1), 2-26.

Nardi, B. (2010). My Life as a Night Elf Priest: An Anthropological Account of World of Warcraft. Michigan, USA: University of Michigan Press.

Nardi, B., \& Harris, J. (2006). Strangers and friends: collaborative play in world of warcraft. Paper presented at the Proceedings of the 2006 20th anniversary conference on Computer supported cooperative work, Banff, Alberta, Canada.

Nardi, B., Ly, S., \& Harris, J. (2007). Learning Conversations in World of Warcraft. Paper presented at the Proceedings of the 40th Annual Hawaii International Conference on System Sciences.

Nevo, S., Nevo, D., \& Kim, H. (2012). From recreational applications to workplace technologies: An empirical study of cross-context IS continuance in the case of virtual worlds. Journal of Information Technology, 27(1), 74-86.

Norman, D. A. (1999). Affordance, conventions, and design. Interactions, 6(3), 38-43.

Nowicka, M., \& Vertovec, S. (2014). Comparing convivialities: Dreams and realities of living-with-difference. European Journal of Cultural Studies, 17(4), 341-356.

Oh, O., Eom, C., \& Rao, H. R. (2015). Research Note-Role of Social Media in Social Change: An Analysis of Collective Sense Making During the 2011 Egypt Revolution. Information Systems Research, 26(1), 210-223.

Orlikowski, W. J., \& Iacono, C. (2001). Research commentary: Desperately seeking the "IT" in IT research - A call to theorizing the IT artifact. Information Systems Research, $12(2), 121-134$. 
Pichardo, N. A. (1997). New Social Movements: A Critical Review. Annual Review of Sociology, 23, 411-430.

Polletta, F., \& Jasper, J. M. (2001). Collective Identity and Social Movements. Annual Review of Sociology, 27, 283-305.

Postmes, T., \& Brunsting, S. (2002). Collective Action in the Age of the Internet: Mass Communication and Online Mobilization. Social Science Computer Review, 20(3), 290-301.

Rappert, B. (2003). Technologies, texts and possibilities: A reply to Hutchby. Sociology, $37(3), 565-580$.

Robinson, B. (2008). Labour's second life: From a virtual strike to union island. In N. Panteli (Ed.), Virtual Social Networks: Mediated Massive and Multiplayer Sites (pp. 134154). Houndmills, New Hampshire: Palgrave Macmillan.

Roquilly, C. (2011). Control Over Virtual World by Game Companies: Issues and Recommendations. MIS Quarterly, 35(3), 653-671.

Saldaña, J. (2016). The coding manual for qualitative researchers (3rd ed.). London: Sage.

Salter, L. (2003). Democracy, New Social Movements, and the Internet. In M. McCaughey \& M. D. Ayers (Eds.), Cyberactivism: Online Activism in Theory and Practice (pp. 117144). New York, NY: Routledge.

Savage, T. A., Harley, D. A., \& Nowak, T. M. (2005). Applying social empowerment strategies as tools for self-advocacy in counseling lesbian and gay male clients. Journal of Counseling and Development, 83(2), 131-137.

Schultze, U. (2010). Embodiment and presence in virtual worlds: a review. Journal of Information Technology, 25(4), 434-449.

Schultze, U. (2014). Performing embodied identity in virtual worlds. European Journal of Information Systems, 23(1), 84-95.

Schultze, U., \& Rennecker, J. (2007). Reframing Online Games. Paper presented at the Proceedings of the International Federation of Information Processing Working Groups 8.2 on Information Systems and Organizations and 9.5 on Virtuality and Society, Portland, Oregon, USA.

Scott, A. (1990). Ideology and the New Social Movements. London, UK: Unwin Hyman Ltd.

Selander, L., \& Jarvenpaa, S. L. (2016). Digital Action Repertoires and Transforming a Social Movement Organization. MIS Quarterly, 40(2), 331-352. 
Shaw, A. (2012). Talking to Gaymers: Questioning Identity, Community and Media Representation. Westminster Papers in Communication \& Culture, 9(1), 67-89.

Sherlock, L. M. (2007). When social networking meets online games: the activity system of grouping in world of warcraft. Paper presented at the Proceedings of the 25th annual ACM international conference on Design of communication, El Paso, Texas, USA.

Sibalis, M. D. (1999). Paris. In D. Higgs (Ed.), Queer Sites: Gay Urban Histories since 1600 (pp. 10-37). London: Routledge.

Staggenborg, S. (2011). Social Movements. New York: Oxford University Press, Inc.

Stanney, K. M., Hale, K. S., \& Zyda, M. (2015). Virtual environments in the 21st century. In K. S. Hale \& K. M. Stanney (Eds.), Handbook of virtual environments: Design, implementation, and applications. New Jersey: Lawrence Erlbaum Associates, Inc.

Stewart, M., \& Schultze, U. (2017). A Performative Identity Perspective of Cyberactivism: The Case of My Stealthy Freedom. Paper presented at the Thirty Eighth International Conference on Information Systems, South Korea.

Stoffregen, T. A. (2003). Affordances as properties of the animal-environment system. Ecological Psychology, 15(2), 115-134.

Strong, D. M., Johnson, S. A., Tulu, B., Trudel, J., Volkoff, O., Pelletier, L. R., . . Garber, L. (2014). A Theory of Organization-EHR Affordance Actualization. Journal of the Association for Information Systems, 15(2), 53-85.

Takavarasha, S., \& Masunungure, E. V. (2016). The Opportunities and Challenges of using Email for Political Communication in Authoritarian States: A Case of Zimbabwe's Media Monitoring Project. In Information Resources Management Association (Ed.), Politics and Social Activism: Concepts, Methodologies, Tools, and Applications (pp. 1488-1507). Hershey, PA: IGI Global.

Tarrow, S. (1994). Power in Movement. New York, NY: Cambridge University Press.

Taylor, T. L. (2008). Does World of Warcraft Change Everything? How a PvP Server, Multinational Playerbase, and Surveillance Mod Scene Caused Me Pause. In H. G. Corneliussen \& J. W. Rettberg (Eds.), Digital Culture, Play, and Identity (pp. 187201). Cambridge, Massachusetts: The MIT Press.

Taylor, T. L. (2009). The Assemblage of Play. Games and Culture, 4(4), 331-339.

Tim, Y., Pan, S. L., Bahri, S., \& Fauzi, A. (2018). Digitally enabled affordances for community-driven environmental movement in rural Malaysia. Information Systems Journal, 28(1), 48-75. 
Turvey, M. T. (1992). Affordances and Prospective Control: An Outline of the Ontology. Ecological Psychology, 4(3), 173-187.

Vaast, E., Safadi, H., Lapointe, L., \& Negoita, B. (2017). Social Media Affordances for Connective Action: An Examination of Microblogging Use During the Gulf of Mexico Oil Spill. MIS Quarterly, 41(4).

Volkoff, O., \& Strong, D. M. (2013). Critical Realism and Affordances: Theorizing ITassociated Organizational Change Processes. MIS Quarterly, 37(3), 819-834.

Vorobjovas - Pinta, O., \& Hardy, A. (2016). The evolution of gay travel research. International Journal of Tourism Research, 18(4), 409-416.

Walsham, G. (1995). Interpretive case studies in IS research: nature and method. European Journal of Information Systems, 4(2), 74-81.

Walsham, G. (2006). Doing interpretive research. European Journal of Information Systems, 15(3), 320-330.

Wasko, M., Teigland, R., Leidner, D., \& Jarvenpaa, S. (2011). Stepping into the Internet: New Ventures in Virtual Worlds. MIS Quarterly, 35(3), 645-652.

Wastell, D., Kawalek, P., Langmead-Jones, P., \& Ormerod, R. (2004). Information systems and partnership in multi-agency networks: an action research project in crime reduction. Information and Organization, 14(3), 189-210.

Wilkins, D. J., Livingstone, A. G., \& Levine, M. (2019). All click, no action? Online action, efficacy perceptions, and prior experience combine to affect future collective action. Computers in Human Behavior, 91, 97-105.

Williams, D., Ducheneaut, N., Xiong, L., Zhang, Y., Yee, N., \& Nickell, E. (2006). From Tree House to Barracks: The Social Life of Guilds in World of Warcraft. Games and Culture, 1(4), 338-361.

Young, A., Summers, J., \& Coursaris, C. (2019). Collective Action, Social Movements and Social Technologies. Paper presented at the Proceedings of the 52nd Hawaii International Conference on System Sciences.

Zammuto, R. F., Griffith, T. L., Majchrzak, A., Dougherty, D. J., \& Faraj, S. (2007). Information technology and the changing fabric of organization. Organization Science, 18(5), 749-762.

Zheng, Y., \& Yu, A. (2016). Affordances of social media in collective action: the case of Free Lunch for Children in China. Information Systems Journal, 26(3), 289-313. 
Zhou, Z., Jin, X.-L., Fang, Y., \& Vogel, D. (2015). Toward a theory of perceived benefits, affective commitment, and continuance intention in social virtual worlds: cultural values (indulgence and individualism) matter. European Journal of Information Systems, 24(3), 247-261. 


\section{APPENDIX}

Application of Klein and Myers' (1999) interpretive principles to this study

\begin{tabular}{|c|c|}
\hline Principle & Application \\
\hline $\begin{array}{l}\text { The Fundamental } \\
\text { Principle of the } \\
\text { Hermeneutic Circle }\end{array}$ & $\begin{array}{l}\text { Examining the whole social movement in a virtual world is not analytically } \\
\text { enough, although it provides a glimpse at social phenomenon within } \\
\text { virtual worlds. To gain a full understanding of this social phenomenon, it } \\
\text { was necessary to examine what specific parts of social movements are } \\
\text { impacted by virtual worlds. Specific issues such as strategies and } \\
\text { campaigns, movement organisation, and recruitment processes. An } \\
\text { analysis of these individual parts of a social movement was necessary to } \\
\text { gain a full understanding of the whole social movement phenomenon. }\end{array}$ \\
\hline $\begin{array}{l}\text { The Principle of } \\
\text { Contextualization }\end{array}$ & $\begin{array}{l}\text { This study focussed on Alpha, which is an LGBT rights movement. This } \\
\text { study also considered the research by Cabiria (2008) who explored how } \\
\text { virtual worlds can act as safe havens for LGBT, and other marginalised } \\
\text { people, where they can develop positive coping skills. }\end{array}$ \\
\hline $\begin{array}{l}\text { The Principle of } \\
\text { Interaction between } \\
\text { the Researchers and } \\
\text { the Subjects }\end{array}$ & $\begin{array}{l}\text { The role of the researcher was that of an involved researcher (Walsham, } \\
\text { 2006). After obtaining permission to conduct the research from Alpha } \\
\text { leaders within WoW, the first author immersed himself in WoW and used } \\
\text { participant observations. }\end{array}$ \\
\hline $\begin{array}{l}\text { The Principle of } \\
\text { Abstraction and } \\
\text { Generalization }\end{array}$ & $\begin{array}{l}\text { Interpretive researchers do not aim at "falsifying" theories but tend to use } \\
\text { theories as a sensitising device. The conceptual framework described in } \\
\text { section } 3.3 \text { was used as a sensitising device for theoretical development. }\end{array}$ \\
\hline $\begin{array}{l}\text { The Principle of } \\
\text { Dialogical Reasoning }\end{array}$ & $\begin{array}{l}\text { The hermeneutic concept of prejudice suggests that prejudice, pre- } \\
\text { judgement, or prior knowledge is important to our understanding. To } \\
\text { confront the prejudices held by the researcher, he spent some time } \\
\text { speaking with members of the gay community to become aware of their } \\
\text { important social conventions and becoming familiar with the terminology } \\
\text { used. }\end{array}$ \\
\hline $\begin{array}{l}\text { The Principle of } \\
\text { Multiple Interpretations }\end{array}$ & $\begin{array}{l}\text { This principle requires that the researcher document multiple viewpoints } \\
\text { within the social context being explored. To achieve this, the researcher } \\
\text { used multiple sources of data to understand the entire picture. }\end{array}$ \\
\hline $\begin{array}{l}\text { The Principle of } \\
\text { Suspicion }\end{array}$ & $\begin{array}{l}\text { Klein and Myers (1999) leave it open that some interpretive researchers } \\
\text { do not choose to follow this principle in their research. This study has } \\
\text { taken this approach in this research, as it did not examine the text from a } \\
\text { critical standpoint. }\end{array}$ \\
\hline
\end{tabular}

